MOUND LABORATORY

Operated By

MONSANTO CHEMICAL COMPANY

: MIAMISBURG，OHIO
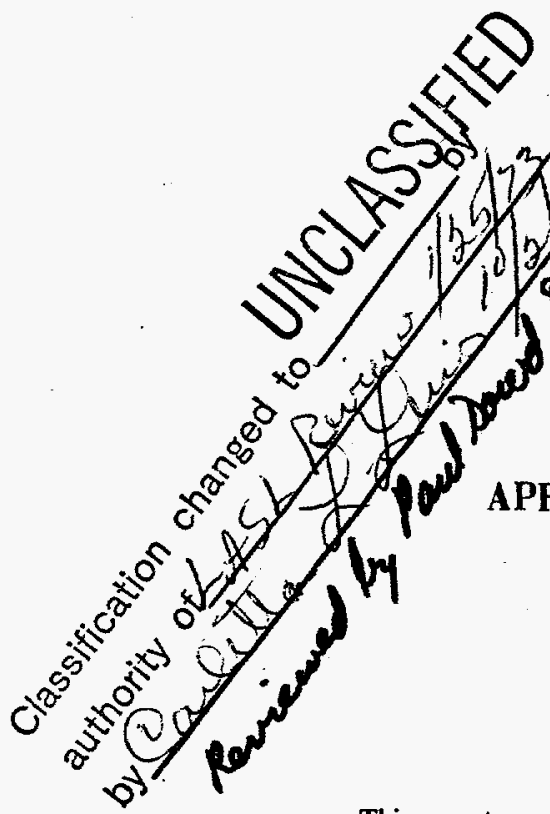

APRIL 2,

(POL

NIUM $\div 208)$

\title{
. ON
}

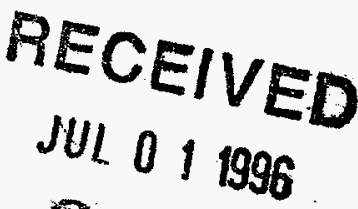

OSTI

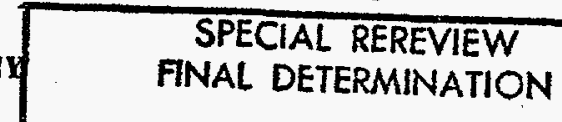

\section{DISCLAIMER}

This report was prepared as an account of work sponsored by an agency of the United States Government. Neither the United States Government nor any agency thereof, nor any of their employees, makes any warranty, express or implied, or assumes any legal liability or responsibility for the accuracy, completeness, or usefulness of any information, apparatus, product, or process disclosed, or represents that its use would not infringe privately owned rights. Reference herein to any specific commercial product, process, or service by trade name, trademark, manufacturer, or otherwise does not necessarily constitute or imply its endorsement, recommendation, or favoring by the United States Government or any agency thereof. The views and opinions of authors expressed herein do not necessarily state or reflect those of the United States Government or any agency thereof.

Date: August 6, 1951

Approved : By:

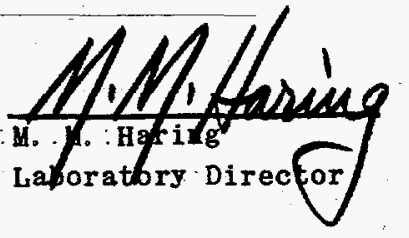

DISTRBUTION OF THS DOCUMENT IS UMMTED
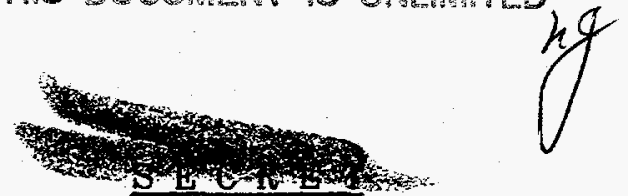

$-1-$ 


\section{DISCLAIMER}

Portions of this document may be illegible in electronic image products. Images are produced from the best available original document. 


\section{UNCLASSIFIED}

\section{DISTR IBUT ION}

1. Carroll A. Hochwalt

2. N. N. T. Samaras

3. J. J. Burbage

4. M. M. Haring

5. R. A. Staniforth

6. D. S. Anthony

7. E. C. Mccarthy

8. J. F, Eichelberger

9. J. E. Bradley

10. J, T. Heyd

11. M. McEwen

12. F. C. Mead, Jr.

13. R. F. Meehan

14. R. A. Miller

15. J. H. Payne, Jr.

16. E. A. Rembold

17. D. L. Scott

18. D. L. Timma

19. L. L. Bentz

20. M. L. Curtis

21. P. M. Engle

22. L. G. Fauble

23. L. B. Gnagey

24. P. M. Hamilton

25. H. L. Hood
26. C. S. Lowe

27. A. W. Martin

28. R. W. Moshier

29. R. G. $01 t$

30. E. Orban

31. W. F, Pesold

32. G. Pish

33. H. Power

34. P. I. Schauer

35. J. G. Stites

36. G. R. Grove

37. J. L, Richmond

38. P. J. Lowry

39. W. D. Prather

40. W. H. WaIdo

41. Area Manager, A.E.C., Dayton, Ohio

42. Area Manager

43. Area Manager

44. D. T. Vier (Los Alamos)

45. Central Files

46. Central files

47. Central Files

48. Central Files

49. Central Files

50. Central files

51. Central Files

Issued: OCT 17195

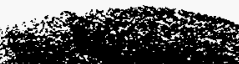




\section{UNCLASSIFIED}

TABLE OF CONTENTS AND MAN :POWER :ANALYSIS

$\cdot($ Polonium-208)

Man Months

SUMMARY

Gamma Activity in Cyclotron-Irradiated Targets,

G. D. Nelson

Polonium Distribution in a Vacuum System,

W. C. McCluggage and W。 H. Power

Processing of Polonium-208 from Proton-Irradiated Bismuth,

G. D. Nelson

Diffusion of Polonium-Bismuth Through Aluminum,

J. B. Otto, Jro and W. H. Power

Loss of Polonium from an Uncovered Bismuth-Polonium Surface, J. B. Ot to, Jro and W. $\mathrm{H}_{0}$ Power
Page

1.0

5.0

$7: 0$

1.5

1.5

16.0

Total 


\section{SUMMARY}

Mound Laboratory is cooperating on a joint development program directed toward the production of polonium-208 by proton irradiation of bismuth. Because of the greater half life of polonium-208 compared with polonium-210 (2.93 years versus 138.4 days), it would be a desirable substitute for polonium-210.

At the present time the Electromagnetic Division of Oak Ridge National Laboratory is operating a cyclotron for the production of polonium-208 on an experimental scale. The targets produced are sent to Mound Laboratory for evaluation of the results which have been obtained, as well as for processing of the targets to obtain experimental amounts. of the polonium in a purified form.

The California Research Corporation is designing the target:to be used in the Mark I linear accelerator located at Livermore, California. The overall responsibility for the Mark. I design and operation is being handled by the California Research and Development Corporation. Before it is used for the production of polonium-208, the Mark I will be converted from a deuteron beam, on which it will first operate, to a proton beam.

Because Mound Laboratory is especially well equipped for the handling of polonium at all levels, a number of problems are being studied as a service function to the design of targets and handling of polonium in both the cyclotron and the linear accelerator. Most of these studies have been carried out with polonium-210,

During the past quarter the amount of polonium-208 received from Oak Ridge has increased from 14 microcuries to 57 millicuries. It has been found possible to dissolve the bismuth and polonium from the targets without dissolving much of the bulkier aluminum backing plate. This procedure would represent a considerable saving in chemicals if production-scale targets were being handled. The polonium in solution after dissolving the targets has been concentrated by electrochemical deposition of the polonium on bismuth powder. Sufficient material has not been obtained for a carrier-free purification of the polonium.

The relative amount of gamma activity found in the targets (based on an equilibrium radium standard as a reference) varied from a minimum of 0.0048 curies of gamma activity per curie of alpha activity to 0.38 curies of gamma per curie of alpha with most of the targets in the range of 0.04 . The gamma activity will undoubtedly be an important consideration in the design of full-scale target processing equipment. There appears to be a correlation between low yields and high gamma activity, which suggests that an appreciable portion of the proton beam is striking the aluminum backing material. Autoradiographs indicate that this result may be due to the melting of the bismuth which results in aluminum being exposed to the beam ( $p .31$ ).

Chemical separations have been carried out on solutions of the bismuth and aluminum from targets in order to identify the gamma activity present. The major gamma emitters found were 14-day bismuth-205 and 6.4-day bismuth-206 produced from the lead impurity in the bismuth, and 72-day cobalt-56, which was found in both the bismuth and aluminum fractions, produced from the iron impurity. The results were confirmed by absorption measure and halflife studies (p. 6).

Four experiments have been run which show the distribution of polonium which is to be expected when polonium is released into a high-vacuum system such as that employed 
in a cyclotron or linear accelerator. While the experiments were run on a laboratory scale, the results indicate that the polonium vapor does deposit on the surfaces which it contacts but no marked improvement in retention results through the use of traps at liquid-air temperatures. Pump oils appear effective in removing residual traces of polonium from the exhaust of the system (p.16).

Experiments which were run on the diffusion of polonium through.aluminum have shown that the polonium penetrated 0.001 -inch aluminum foil through micropores rather than by diffusion. The amount of diffusion, indicated by the straggling curves run on both sides of the aluminum, was slight. The results are in agreement with those obtained by the California Research Corporation. It is concluded that the 20-mil aluminum cover plate for the Mark I solid target will provide adequate protection against polonium diffusion. No further work is planned on this project (p. 43).

The use of uncovered bismuth targets in the oak Ridge cyclotron has indicated that polonium contamination will be a serious problem at higher. levels of production. The use of grazing incidence targets necessitates the use of extremely thin coverings for the bismuth if protective covers are used at all. Preliminary experiments have been directed toward determining the rate of polonium loss to be expected from an uncovered target at a given surface temperature (p. 49). 
Problem Title - Gamma Activity in Cyclotron-Irradiated Targets

Report By - G. D. Nelson

Work Done By - G. D. Nelson

\section{INTRODUCTION}

Since the amount of gamma activity produced may make it necessary to limit the quantity of polonium-208 which is produced in a given target, a study of the gammactivity and the impurities responsible for it was begun. The short half-life gamma.activity present in proton-irradiated, $2 S$ aluminum has been reported by Oak Ridge. National Laboratory. ${ }^{1}$ The Oak Ridge study was begun immediately following bombardment when the shorter half-life gamma emitters were most intense and the effects of the longer half-life material, which we were able to detect at Mound several days after bombardment, were masked. The Cak Ridge study revealed a 0.5 -hour half 1 ife on the target and holder (possibly a mixture of activities), a 9-hour half life (probably zinc-62), a 13-hour half life (probably copper-64), and a 38-minute half life (probably zinc-63).

Since several days elapsed between the bombardment and the assay dates for the sample studied, these shorter-lived isotopes would have decayed. The study was begun on the activity remaining in the solution of the aluminum backing from Target 10 (10 days after bombardment) and the solution of the bismuth from Target 11 (14 days after bombardment). These samples were selected because they were the most gauma-active on hand when this work was begun.

\section{DETAILED REPORT}

The study of gamma emitters was begun on the solution of the bismuth chloride from Target 11 after the solution had been assayed for polonium-208. The alpha activity was removed from the solution by electrochemical deposition on bismuth powder. Chemical separations were made with carriers of several milligrams each of the possible gamna emitters which could be produced by proton reactions on the inpurities in the bismuth (Table I). An outline of the method of analysis and the results of gamma counts on the solutions of each of the separated elements are given in Table II. A half-life study was begun and halfthickness measurements were made May 10 (Figures 1 and 2 ). From the half-thickness measurement the energy of the gamma rays in million electron volts may be obtained. ${ }^{2}$

It would appear that bismuth-205" (14 day), bismuth-206 (6.4 day), and cobalt-56 (72 day) account for the major part of the gamma activity in the bismuth present 14 days after bombardment. ${ }^{3}$ The half-life study indicates that some material of longer than 14-day half life was present in the bismuth fraction. This longer-lived activity may be cobalt-56 carried with the relatively large amount of bismuth present or possibly some other activity which would precipitate in the acid sulfide group.

From the chemical separations, half-thickness measurements, and half-life studies made on the aluminum back of Target 10 , it was found that 72 day cobalt-56 is the predominating gamma emitter present in the target backing 10 days after bombardment (Figures 3 and 4. Tables III and IV $)^{3}$ Periodic gamma counts were made on the cobalt fraction from the chemical separations made on the aluminum of Target 10 (Sample 4) and on a portion of the original solution of the aluminum backing from Target 10 (Sample. 5). Cobalt fractions from

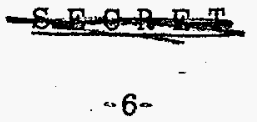


the chemical separations carried out on the bismuth from Target 11 were also: counted. All three samples follow the same decay curve, namely that of 72 -day cobalt-56.

\section{CONCLUS IONS}

The : gamma emitters in the proton-irradiated bismuth targets : two weeks after bombardment are chiefly bismuth-205 and -206 and cobalt-56. The gamma activity in the aluminum backing consists mainly of cobalt-56.

\section{REFERENCES}

1. Charpie, R. A., Minutes of Joint Meeting on Polonium-208 held at Mound Laboratory on April 23-24, 1951. Central Files No. $51-4 \div 83$.

2. Gentner, W., J. phys radium, $7,6,274,:(1935)$.

3. "Nuclear Data", U. S. Dept, of Commerce, Nat. Bur. Stds., (1950). 


\section{TABLE : I}

'POSSIBLE GAMMA ACTIVITY ON IIMPURITIES IN BISMUTH*

IMPURITY

$\mathrm{Ag}$

$\mathrm{Fe}$

$\mathrm{Cu}$

As

$\mathrm{Sb}$

$\mathrm{Pb}$

Si

$\mathrm{Cr}$

Al

$\mathrm{Mg}$
SPECTROGRAPHIC

ANALYSIS

$\left(p p m_{0}\right) * *$

0.2

10

3

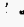

50

100

10

20

10
PRODUCT

$\mathrm{Cd}^{115}$

$\mathrm{Cd}^{108}$

$\mathrm{Co}^{58}$

$\mathrm{Co}^{57}$

$\mathrm{Co}^{58}$

$\mathrm{Zn}^{85}$

$S e^{75}$

$\mathrm{Te}^{118}$

$\mathrm{Te}^{1,21}(\mathrm{~m})$

$\mathrm{Te}^{\mathrm{1} \cdot 21}$

$\mathrm{Te}^{123}$

$\mathrm{Bi}^{205}$

$\mathrm{Bi}^{206}$

$\mathrm{Mn}^{52}$

$\mathrm{Mn}^{54}$

310
14

$6: 4$

6.5

HALF LIFE

(days)

43

330

80

270

72

250

127

4:5

143

17

90 
TABLE $\mid$ I

GAMMA ACTIVITY PRODUCED ON IMPURITIES IN BISMUTH*

$\begin{array}{ccccc} & & & & 5 / 9 / 51 \\ \text { PER CENT } & & \\ \text { OF TOTAL } \\ \text { COUNTS }\end{array}$

* The gamma activities listed were produced by proton reactions in Sample 11.

FLOWSHEET FOR BISMUTH ANALYSIS

Solution of Te, Se, $\mathrm{Zn}, \mathrm{Co}, \mathrm{Cd}, \mathrm{Bi}$

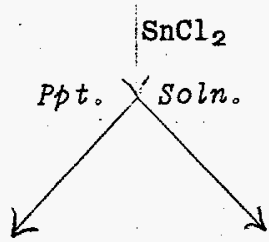

$\mathrm{Te}$ and $\mathrm{Se}$

$\mathrm{Zn}, \mathrm{Co}, \mathrm{Cd}, \mathrm{Bi}$
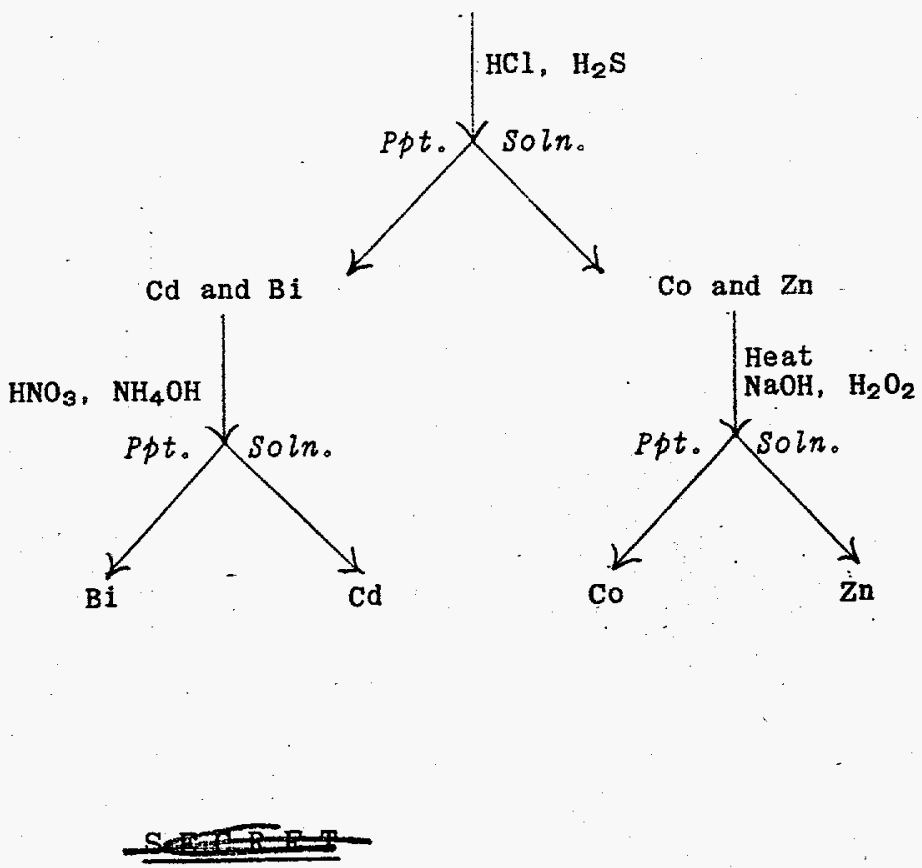
TABLE III

POSSIBLE GAMMA ACTIVITY ON IMPURITIES IN ALUMINUM*

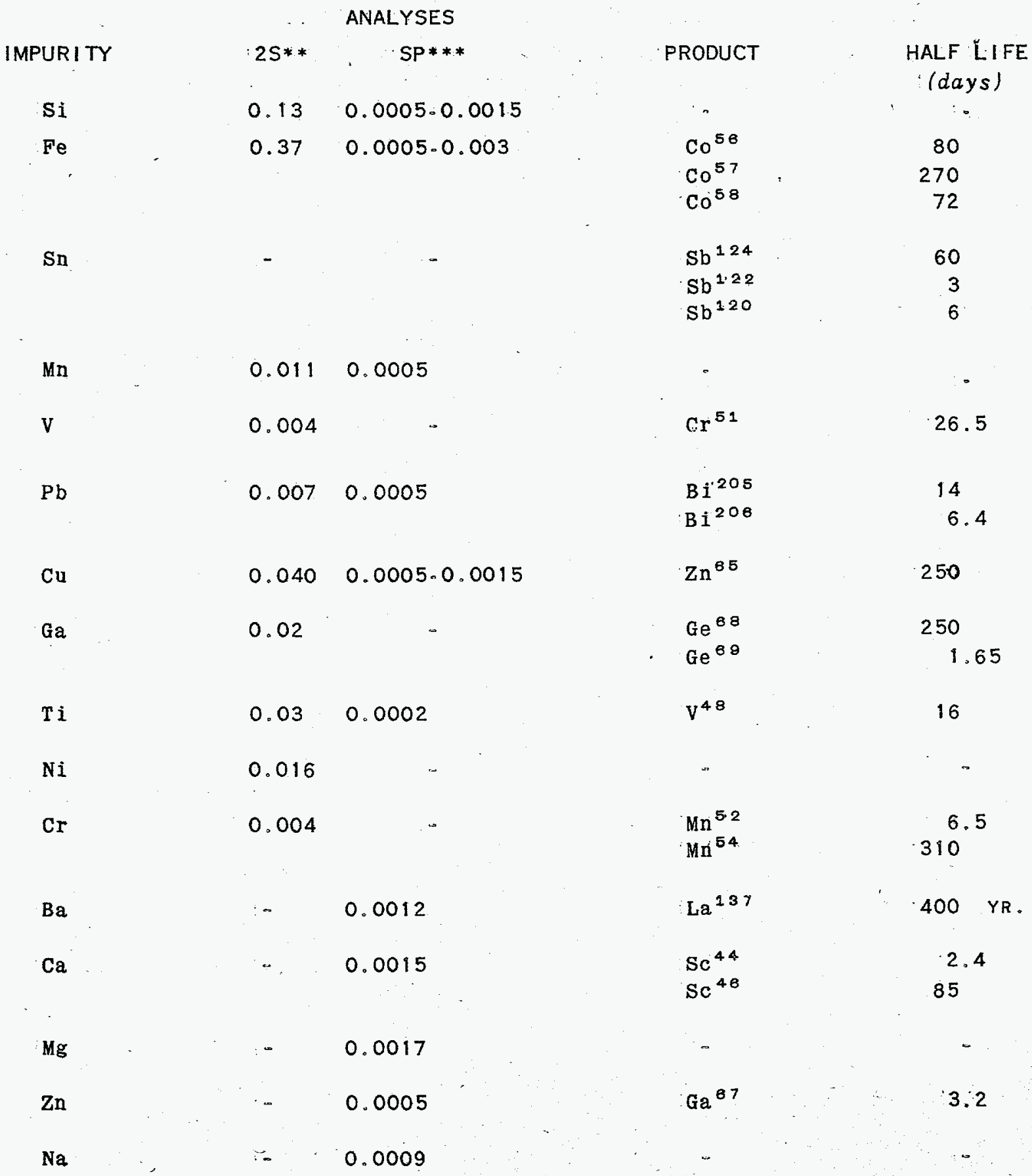

* The gamma : activities listed are those with a half life greater than one day formed by P.N AND P. $2 N$ REACTIONŚ.

** analyses by D. L. Timma 2S aluminum is the highest purity commercial aluminum AEL VALUES \pm 50 PER CENT. SUPPLIED IN THIS COUNTRY: AND IS ABOUT \$O.18 PER POUND.

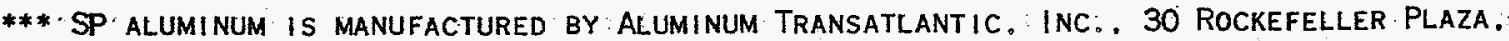
NEW YORK 20 . N. Y. NOTCHED INGOTS OF 22 POUNDS ARE QUOTED AT \$O.28 PER POUND F.O.B. NEW YORK. DUTY PAID. 
TABLE IV

GAMMA ACTIVITY PRODUCED ON IMPURITIES IN ALUMINUM*

\begin{tabular}{|c|c|c|c|c|c|}
\hline \multirow[b]{3}{*}{ IMPUR ITY. } & \multicolumn{3}{|c|}{ RUN 1} & \multicolumn{2}{|r|}{ RUN 2} \\
\hline & ACTIVITY & \multicolumn{2}{|r|}{ PER CENT OF } & \multicolumn{2}{|r|}{ PER CENT OF } \\
\hline & PRODUCED & COUNTS & $\begin{array}{l}\text { TOTAL COUNTS } \\
5 / 1 / 51\end{array}$ & COUNTS & $\begin{array}{l}\text { TOTAL COUNTS } \\
5 / 4 / 51\end{array}$ \\
\hline $\mathrm{Cu}$ & $\mathrm{Zn}$ & 44.8 & 5.22 & 48.8 & 5.80 \\
\hline $\mathrm{Ni}$ & $\mathrm{Cu}$ & 6.2 & 0.72 & 2.9 & 0.35 \\
\hline$M n$ & $\mathrm{Fe}$ & 8.2 & 0.95 & 16.9 & 2.01 \\
\hline $\mathrm{Cr}$ & Mn & 40.3 & 4.70 & 37.8 & 4.50 \\
\hline $\mathrm{Fe}$ & Co & 727.1 & 84.71 & 708.8 & 84.34 \\
\hline & & 826.6 & 96.3 & 815.2 & 97.0 \\
\hline
\end{tabular}

* The gamma activities listed were produced by proton reactions in Target 10

FLOWSHEET FOR ALUMINUM ANALYSIS

(AFTER NOYES AND BRAY)

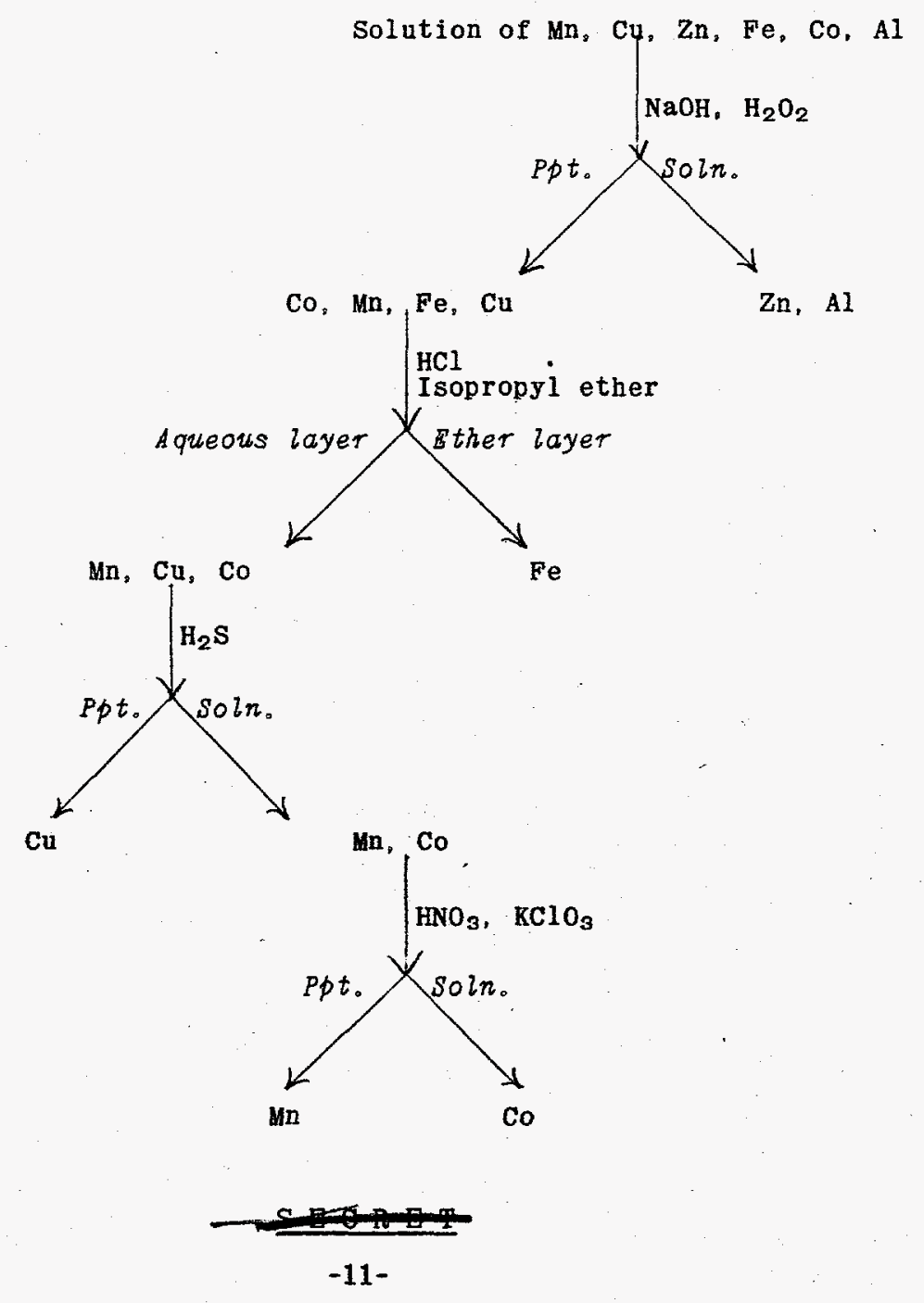




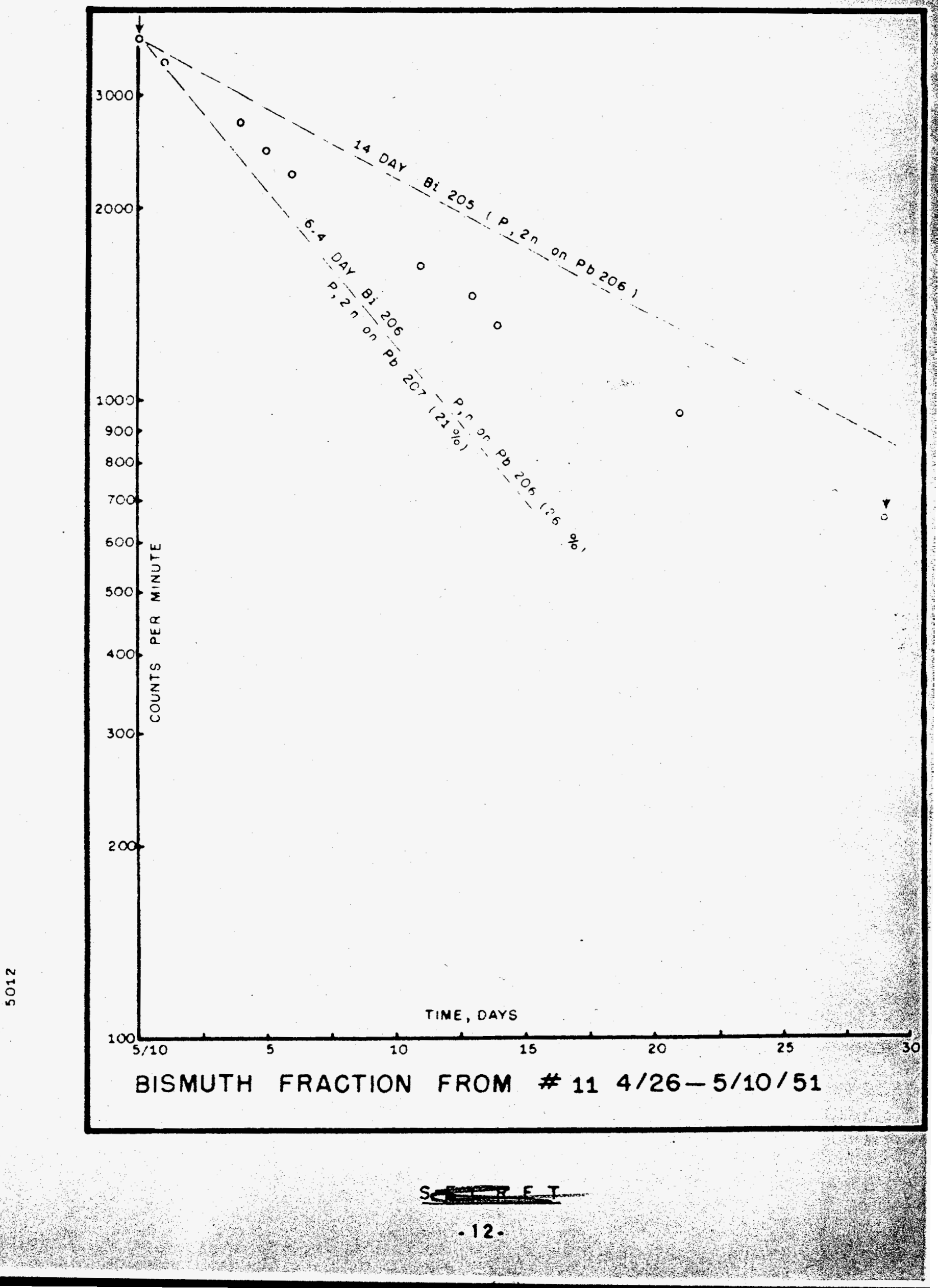




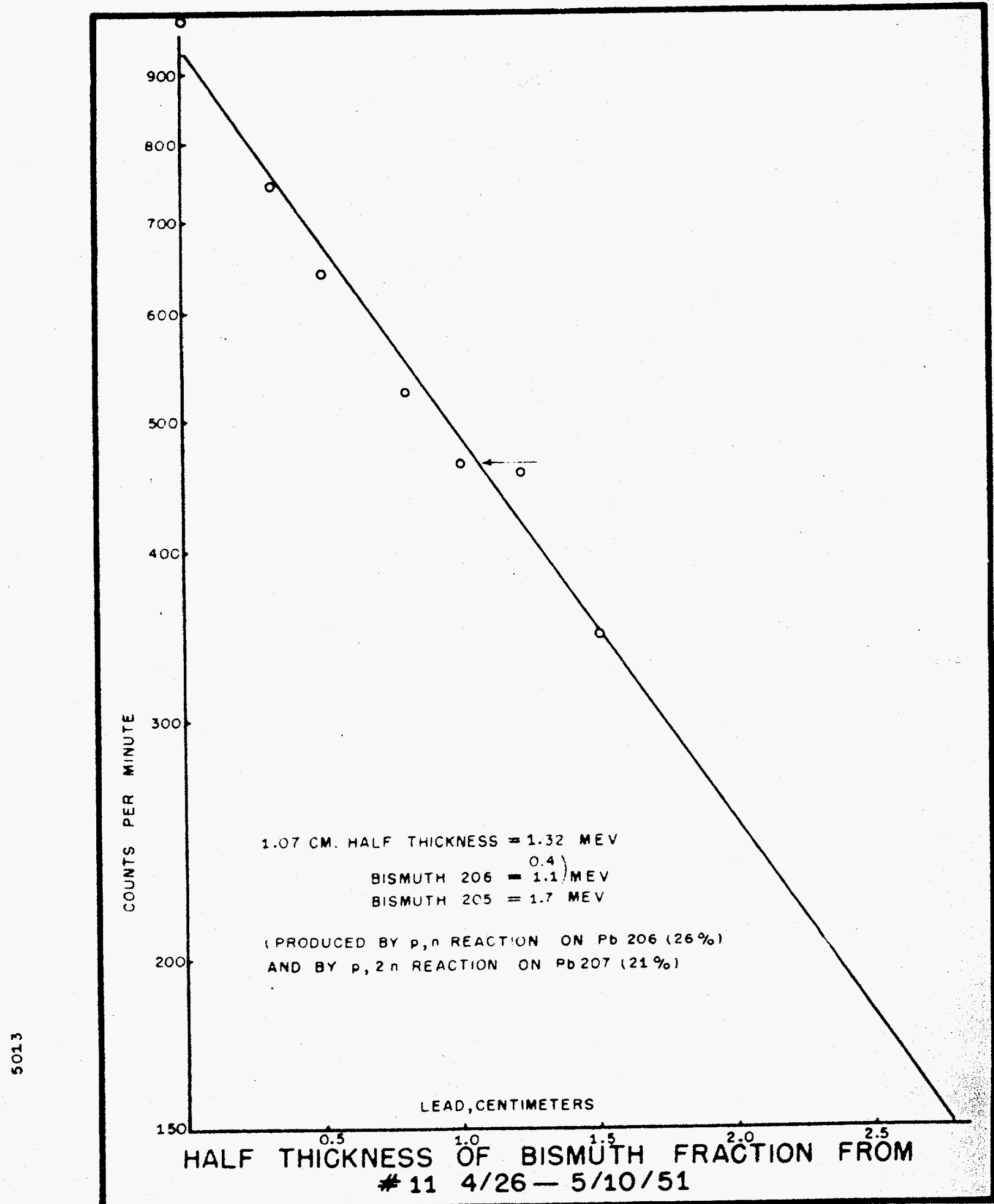




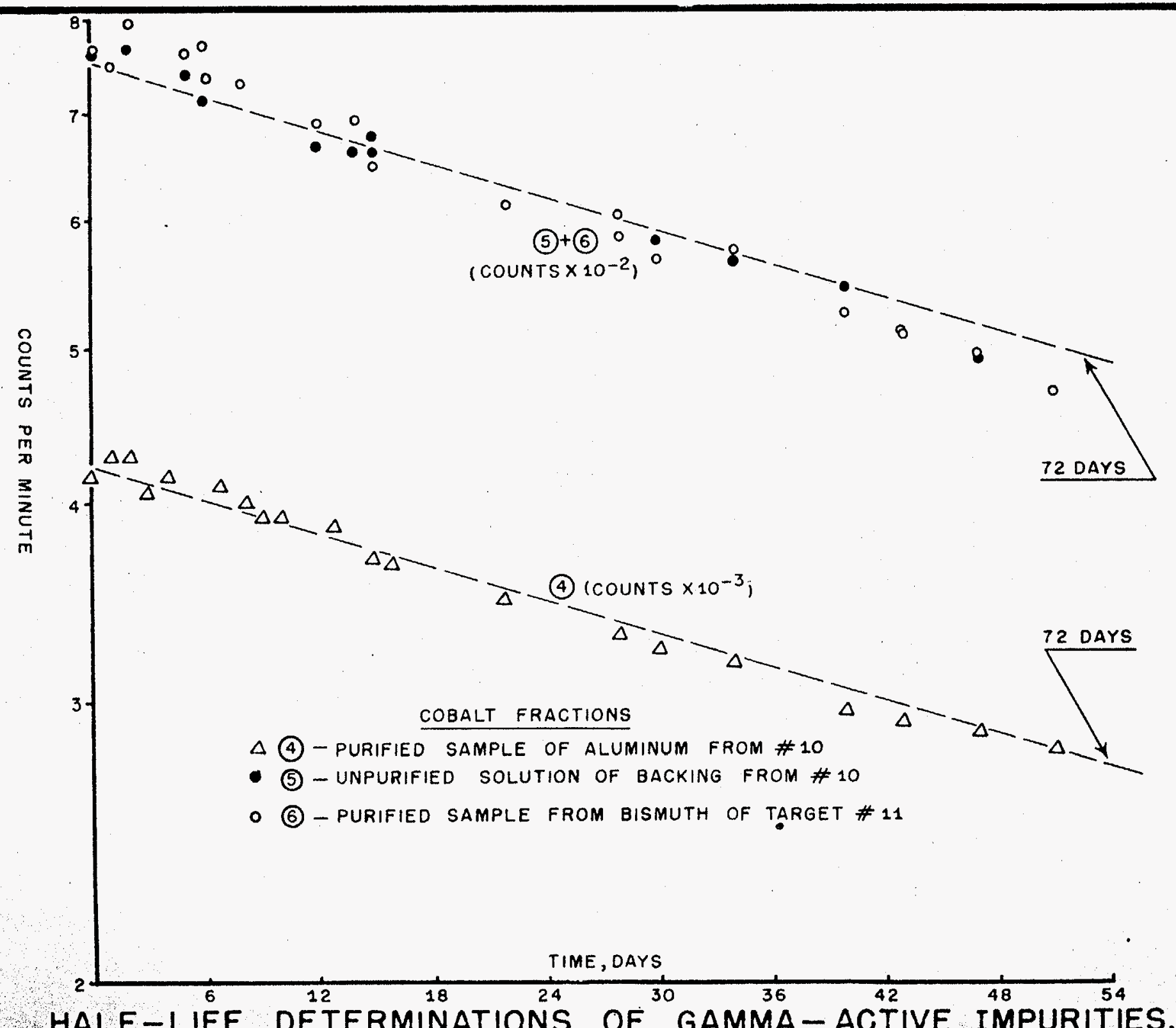

$\frac{n}{c}$ 


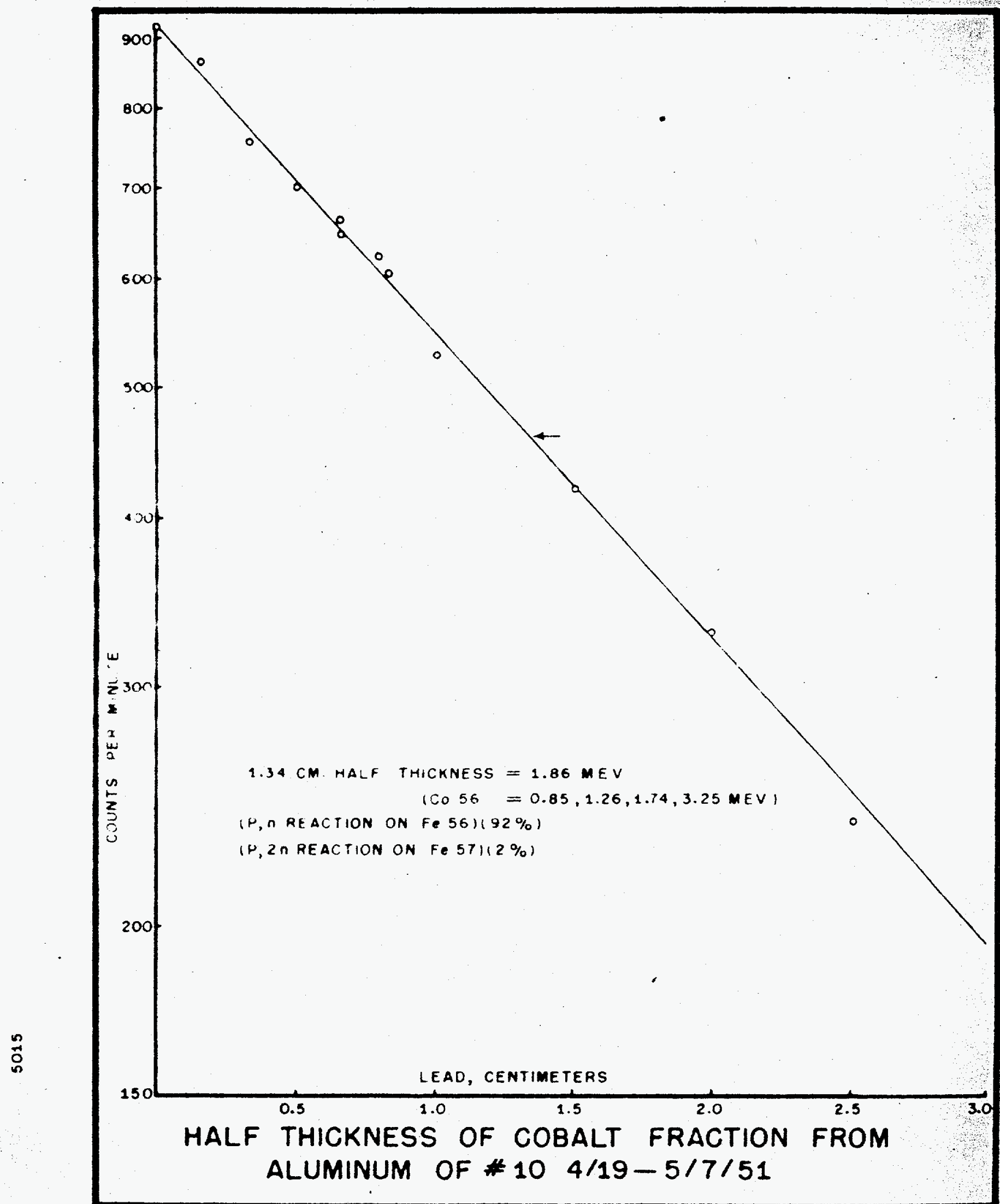

\section{UNCLASSIFIED}


Problem Title - Polonium Distribution in a Vacuum System

Report By - W. C. McCluggage and W. H. Power

Work Done By - w. c. Mccluggage and $\boldsymbol{J}_{\text {。 }}$ S. Kochendorfer

\section{INTRODUCTION}

The possibility of serious contamination of a cyclotron or linear accelerator during the proton irradiation of the bismuth targets used in the production of polonium-208 has indicated the need for a study of polonium distribution in a vacuum system.

\section{DETA ILED : REPORT}

A vacuum system made up of essentially the same components (traps, pumps, etc.) as used in the cyclotron or accelerator was contaminated with known quantities of polonium distilled from a pure sample or from a bismuth mixture, and the distribution of the polonium was measured.

Four runs were made, each with modifications of the same general type of apparatus. In each case, polonium was evaporated in a volatilization flask which was connected to one or two cold traps, a three-stage oil diffusion pump, and a Welch "Duo".Seal" fore pump. The exhaust from the fore pump was passed through a liquid nitrogen trap filled with glass wool and then through a respirator-type filter. All parts of the apparatus were analyzed for polonium to determine quantitatively the manner in which polonium was distributed in the vacuum system and pump exhaust. Glass apparatus was leached with aqua regia, and the solution was alpha counted. Oil samples were extracted with concentrated nitric acid or "thicksample" counted in a proportional counter."

Run No. 1

Polonium-210 was volatilized from a platinum foil placed in a quartz boat. A tungsten filament placed at the center of a 500-milliliter round bottom flask both supported and heated the boat. The flask was connected to an 8 inch dry ice-acetone trap (Figure 1). The polonium content of the various parts of the vacuum system is shown in Table I. Most of the volatilized polonium was condensed in the volatilization flask. About one per cent of the polonium was in the line and trap adjacent to the volatilization flask, and only traces entered the diffusion oil and fore-pump oil. No detectable polonium could be observed in the vacuum-pump exhaust. A 64-hour exposure of the volatilization flask and dry ice trap in a darkened room is shown by Figure 2. Some fluorescence of the walls of the dry-ice trap can be seen.

Run No. 2

Since the evaporation pattern of polonium from a bismuth target is the subject of major concern of this study, a second experiment was run in which the polonium was dissolved in bismuth before being volatilized. The apparatus for Run No. 2 is essentially the same as for Run No 1 (Figure 1). A thermocouple was inserted in the bismuth pellet and another attached to the flask wall. Conditions for the volatilization are given in Table II. The distribution af bismuth after the volatilization can be seen in the form of a bismuth mirror (Figure 3). A photograph of the apparatus taken in total darkness except for the fluorescence of the polonium is shown by Figure 4 . As was expected, the most intense fluorescence was directly upward from the open quartz boat. The diminution in intensity of

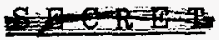


fluorescence under the boat appears:as a shadow on the lower half of the flask. No fluorescence of the traps was detected. The distribution of polonium in the vacuum system is given in Table III.

Less polonium was detected in the dry-ice trap from volatilization of a poloniumbismuth slug (Run No. 2) than from volatilization of pure polonium : (Run No. 1). On the other hand, more polonium was detected in the pump oils and in the pump exhaust from Run No: 2 than from Run No. 1.

A pair of experiments (Runs No. 3 and 4 ) was designed to determine the effectiveness of a liquid-nitrogen trap as compared to a room-temperature trap. The apparatus shown by Figure 5 was constructed in duplicate. The volatilization chamber was arranged so that more of the polonium would be forced into the trapping system than in the case of Runs No. 1 and 2. During Run No. 3 the trap adjacent to the volatilization tube was kept at room temperature and the second trap immersed in liquid nitrogen, During Run No. 4 both traps were immersed in liquid nitrogen.

Run No. 3

A slug of bismuth weighing 0.997 gram containing 1.19 curies of polonium was heated in a quartz boat according to the schedule given in Table. IV. Heating conditions were less severe for Run No. 3 than for Run No. 2, so less polonium was volatilized. however, the closer proximity of the volatilization chamber to the trap in the case of Run No. 3 permitted more polonium to enter the trap. The rather large deposit of activity in the first trap held at room temperature (Figure 6 ) is believed to be caused principally by the effect of the right-angle bend in stopping and condensing polonium vapor. A photograph shows the fluorescence of activity in the volatilization chamber (Figure 7).

Run No. 4

A slug of bismuth weighing 0.9838 gram containing 1.19 curies of polonium was heated in a quartz boat to $510^{\circ} \mathrm{C}$. over a period of $1 \frac{1}{2}$ hours. A detailed record of the heating schedule is not available because the potentiometer in the thermocouple circuit failed. The bismuth slug was held at $510^{\circ} \mathrm{C}$. for $4 \frac{1}{4}$ hours at a pressure of $3.4 \times 10^{-8}$ millimeter. The bismuth residue which remained in the boat was coated with a yellow material, probably the oxide, whereas residual bismuth from other runs was metallic in appearance.

Although approximately the same quantity of bismuth was volatilized during Runs No. 3 and 4 , about twice as much polonium was found in the two traps of Run No. 4 than in the two traps of Run No. 3. The distribution of polonium in the vacuum systems for Runs No. 3 and 4 is given in Table $v$.

\section{DISCUSS I ON}

No evidence has been obtained to demonstrate that low-temperature traps have any marked advantage over traps operated at room temperature in collecting polonium. It is felt that as long as the polonium-bismuth vapor is given a chance to cool to room temperature, further cooling will not increase trapping efficiency. The factors which are probably influential upon the polonium-distribution pattern after volatilization and condensation are particle size and concentration of the condensed vapor, gas pressure, rate of gas flow in the system, and the geometry of the system. A filter of fine porosity or a scrubbing tower in the vacuum line before a pump would probably be an effective means of 
preventing polonium from contaminating the pump. Such filters or scrubbing towers in a vacuum system might, of course, retard or prevent the attainment of a high vacuum.

Although traces of polonium were detected in the fore-pump exhaust of some runs, the pump oil in all cases acted as an efficient trap for polonium particles. If the unfiltered pump exhausts had been discharged into the room instead of into the hood, no appreciable contamination would have resulted. The filtered vacuum-pump exhaust could have been discharged directly to the room without detectable contamination.

The consistent lack of material balance of polonium recovery in spite of repeated leachings of glass apparatus with aqua regia indicates that around 10 per cent of the volatilized polonium was retained in the glass.

\section{REFERENCE}

1. Nelson, G. D., Rpt. Gen。Res., MLM-559, p. 16, May $21,1951$. 
TABLE $\mid$

\section{DISTRIBUTION OF POLONIUM IN A VACUUM SYSTEM}

\section{LOCATION}

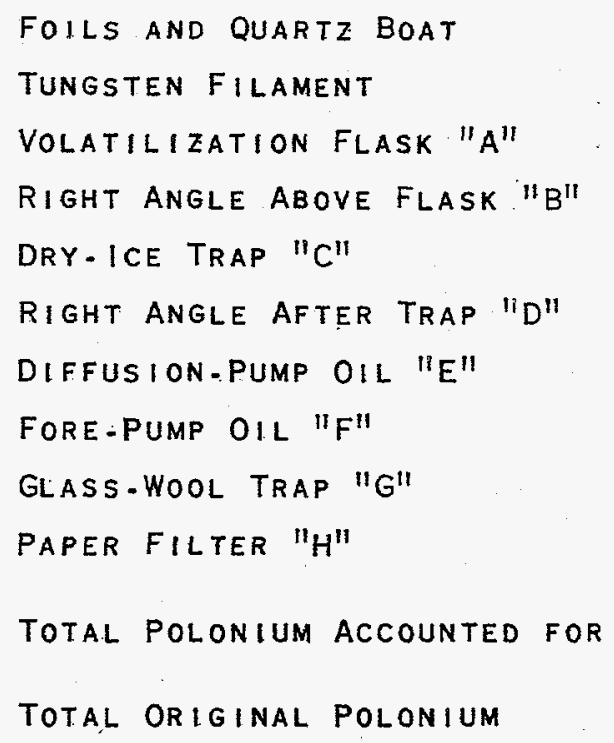

RUN NO. 1

POLONIUM
CONTENT
(curies)

0.200

0.0045

0.60

0.0048

0.0024

$2.7 \times 10^{.8}$

$2 \times 10^{-7}$

$1 \times 10^{-7}$

$$
<10^{-11}
$$$$
<10.11
$$

0.812

0.91
DISTRIBUTION OF THE VOLATILIZED POLONIUM (per cent)

84.5

0.68

0.34

$3.8 \times 10^{-6}$

$3 . \times 10^{-5}$

$1 \times 10^{-5}$

$<10^{-8}$

$<10^{-\theta}$ 
TABLE I

CONDITIONS FOR THE VOLATILIZATION OF POLONIUM

RUN NO.' 12

$\begin{array}{cc}\begin{array}{c}\text { TEMPERATURE } \\ \text { OF BI SMUTH } \\ \text { SLUG } \\ \left({ }^{\circ} \mathrm{C} . \text { ) }\right.\end{array} & \text { TIME AT DESIGNATED } \\ & \begin{array}{c}\text { TEMPERATURE } \\ \text { (Minutes) }\end{array} \\ 60 & 5 \\ 120 & 12 \\ 183 & 12 \\ 220 & 12 \\ 270 & 12 \\ 290 & 12 \\ 312 & 19 \\ 343 & 13 \\ 355 & 38 \\ - & 10 \\ 403 & 8 \\ 445 & 4 \\ 515 & 8 \\ 550 & 4 \\ 570 & 165\end{array}$

TEMPERATURE OF
WALL OF FLASK
$\left({ }^{\circ} \mathrm{C}.\right)$

$\cdots$
30
35
35
40
40
44
45
49
$\cdots$
50
53
63
65
85

P.RESSURE OF VACUUM SYSTEM

( $m$ 。 $\mathrm{Hg}$ )

$2.3 \times 10^{-8}$

$2.3 \times 10^{-8}$

$1 \times 10.5$

$1 \times 10.5$

$1.6 \times 10^{.5}$

$2.0 \times 10^{-5}$

$3.4 \times 10^{-5}$

$3.6 \times 10^{.5}$
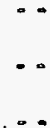

$10^{-4}$
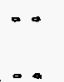

$5.0 \times 10^{-8}$

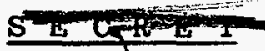


TABLE 111

\section{DISTRIBUTION OF POLONIUM IN A VACUUM SYSTEM}

RUN NO. 2

\section{LOCATION}

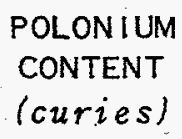

POLONIUM CONTENT (curies)

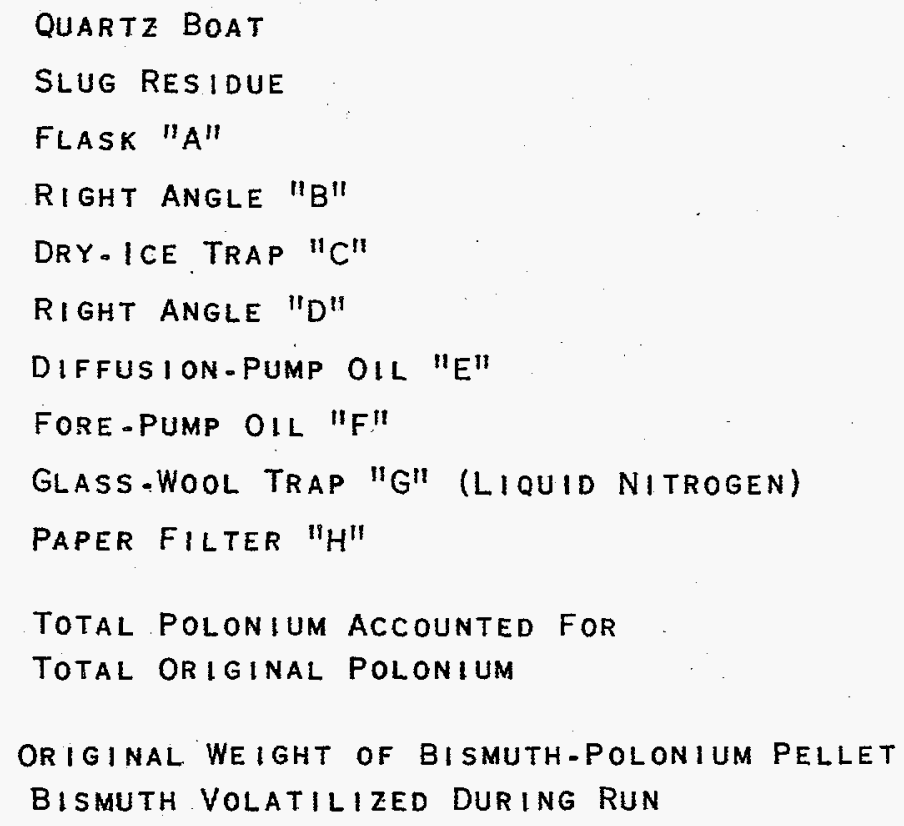

ORIGINAL WEIGHT OF BISMUTH-POLONIUM PELLET BISMUTH VOLATILIZED DURING RUN

$0.993 G$. 0.0155 .6 .
89.6

0.19

$1.8 \times 10^{.3}$

$5.0 \times 10^{.4}$

$4.3 \times 10^{-3}$

$3.1 \times 10^{-4}$

$1.7 \times 10^{-5}$

$2 \times 10^{\circ} 8$ 


\section{TABLE IV}

\section{CONDITIONS FOR. THE VOLATILIZATION OF POLONIUM}

RUN NO. 3

TEMPERATURE

$$
\left({ }^{\circ} \mathrm{C} .\right)
$$

103

190

530

520

500

490

490

508
TIME AT DESIGNATED TEMPERATURE

(Minutes)

22

13

25

8

10

8

5

75
PRESSURE OF VACUUM SYSTEM

( $m$ 。 $\mathrm{Hg}$ )

$5 \times 10^{-6}$

$4 \times 10^{-8}$

$3 \times 10^{\circ} \theta$

$2.2 \times 10^{-6}$

$2.2 \times 10^{-6}$

$2.2 \times 10^{-8}$

$2.0 \times 10^{-6}$

$2.0 \times 10^{-6}$ 
TABLE V

DISTRIBUTION OF POLONIUM IN VACUUM SYSTEMS

LOCATION

SLug Residue

VOLATILIZATION TUBE "A"

TRAP "B"

TRAP "C"

RIGHT ANGLE "D"

DIFFUS ION.PUMP OIL "E"

FORE.PUMP OIL "F"

GLASS.WOOL TRAP "G"

(LIQUID NITROGEN)

PAPER FILTER " $H$ "

TOTAL ACCOUNTED FOR

TOTAL ORIGINAL POLONIUM

ORIGINAL WEIGHT OF

BISMUTH.POLONIUM PELLET

BISMUTH VOLATILIZED DURING RUN
0.471

0.613

$0.016 *(R T)$

$6.1 \times 10^{.5}(\mathrm{LN})$

$1.3 \times 10^{.5}$

$1.1 \times 10^{-7}$

$1.2 \times 10^{-8}$

$2.8 \times 10^{-7}$

$<10^{-11}$

1.100

1.19

$\begin{array}{lc}\text { RUN NO. } 4 \\ \text { POLONIUM } & \text { VOLATILIZED } \\ \text { CONTENT } & \text { POLONIUM } \\ \text { (Cuties) } & \text { (per cent) }\end{array}$

RUN NO: 3

VOLATILIZED

POLONIUM

(per cent)

CONTENT
(Curies)
0.334

85.2

$2,2 *$

$8.5 \times 10^{-3}$

$1.8 \times 10^{-3}$

$1.5 \times 10^{.5}$

$1.7 \times 10^{.8}$

0.722

$0.035 *$ (LN)

$1.6 \times 10^{-4}(\mathrm{LN})$

$4.8 \times 10^{-8}$

$4.6 \times 10^{.6}$

$1.1 \times 10^{.5}$

$3.9 \times 10^{-5}$

$<10^{\prime} \theta$

$7.9 \times 10^{.8}$

$7 \times 10^{-11}$

1.091

1.19
84.0

$4.1 *$

$1.8 \times 10^{22}$

$5.6 \times 10^{-4}$

$5.3 \times 10^{-4}$

$1.3 \times 10^{.3}$

$9.2 \times 10^{-4}$

$8 \times 10^{-8}$

* most of deposit at right-angle bend.

0.997 G.

0.9838 . .

RT ROOM-TEMPERATURE TRAP.

LN LIQUID-NITROGEN TRAP.

$0.0071 . G$ 


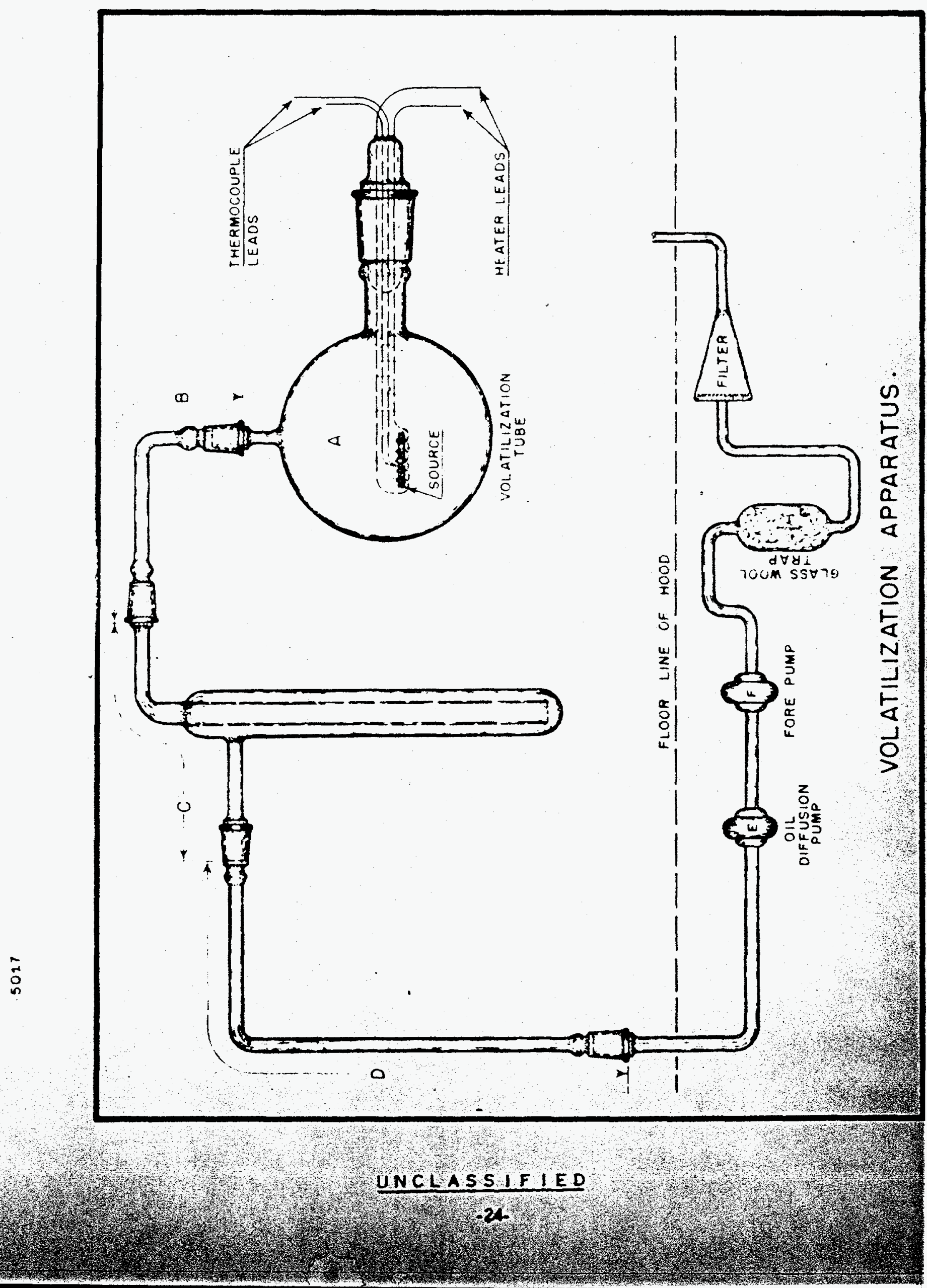




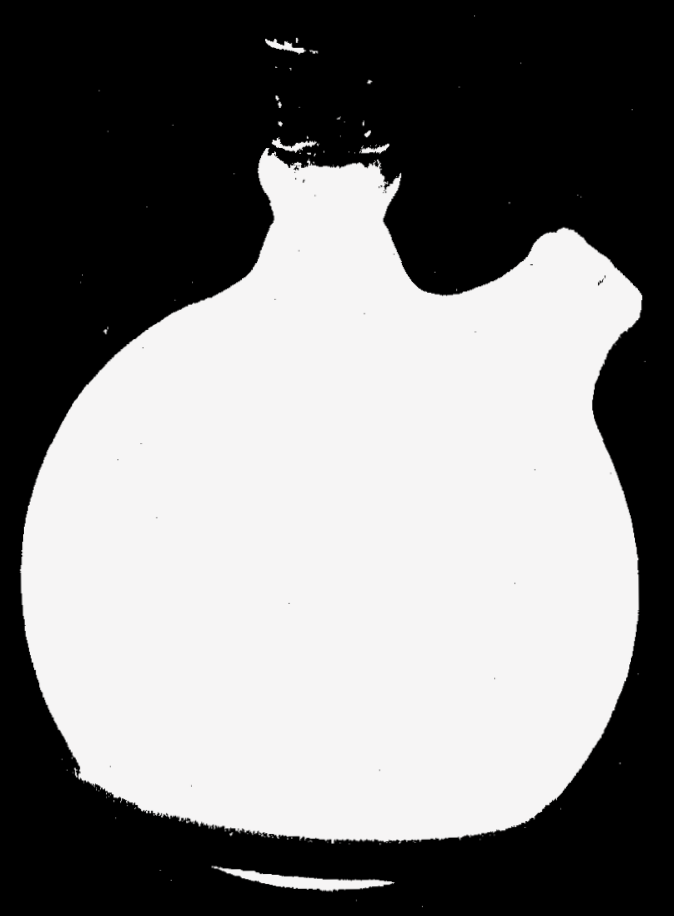

FLUORESCENCE OF VOLATILIZATION CHAMBER AND TRAP AFTER RUN NO. 1 EXPOSURE 64 HOURS AT F 4.5 


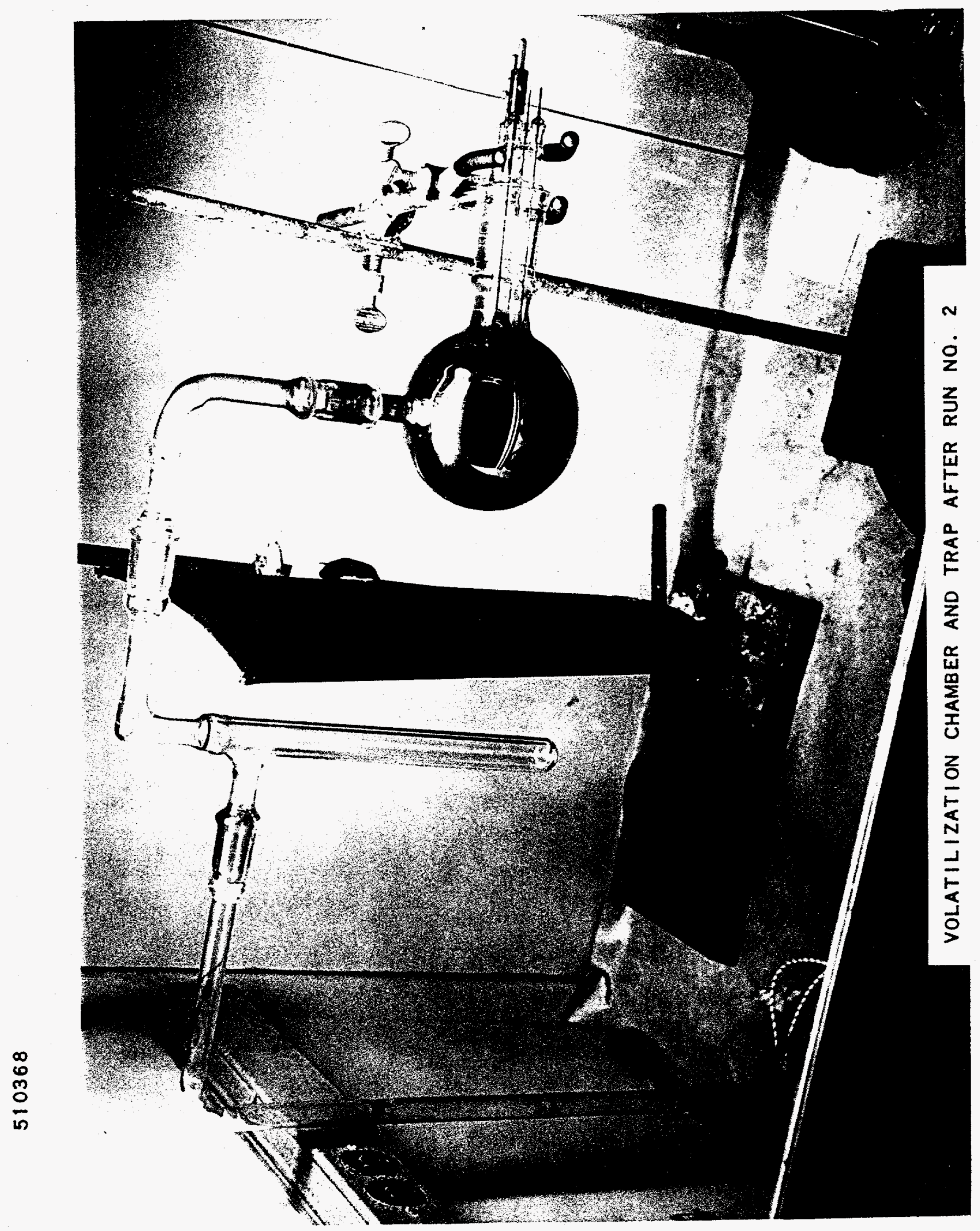

UNCLASS IF IED 


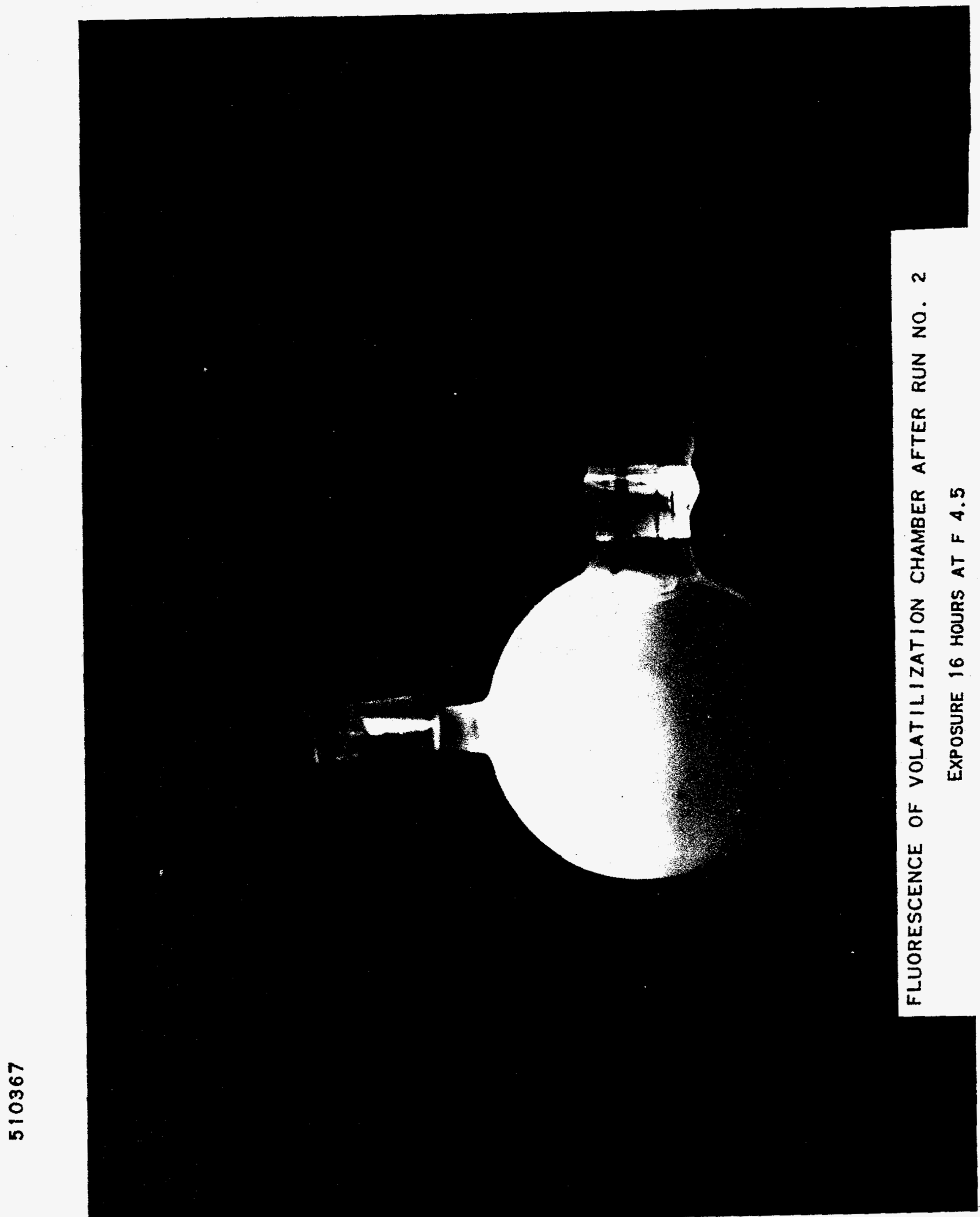

UNCLASSIFIED 


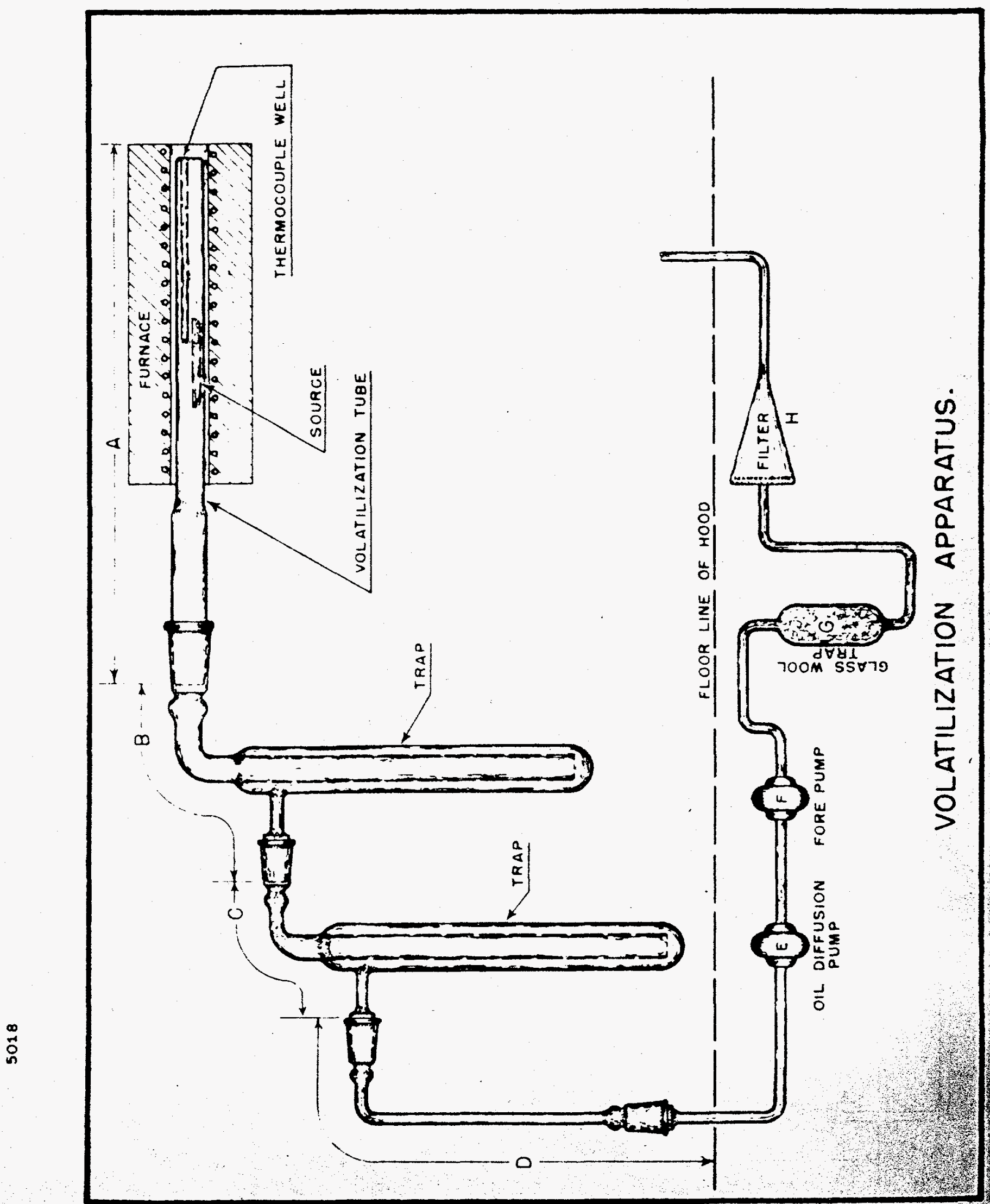

UNCLASS /F:IED

a. 


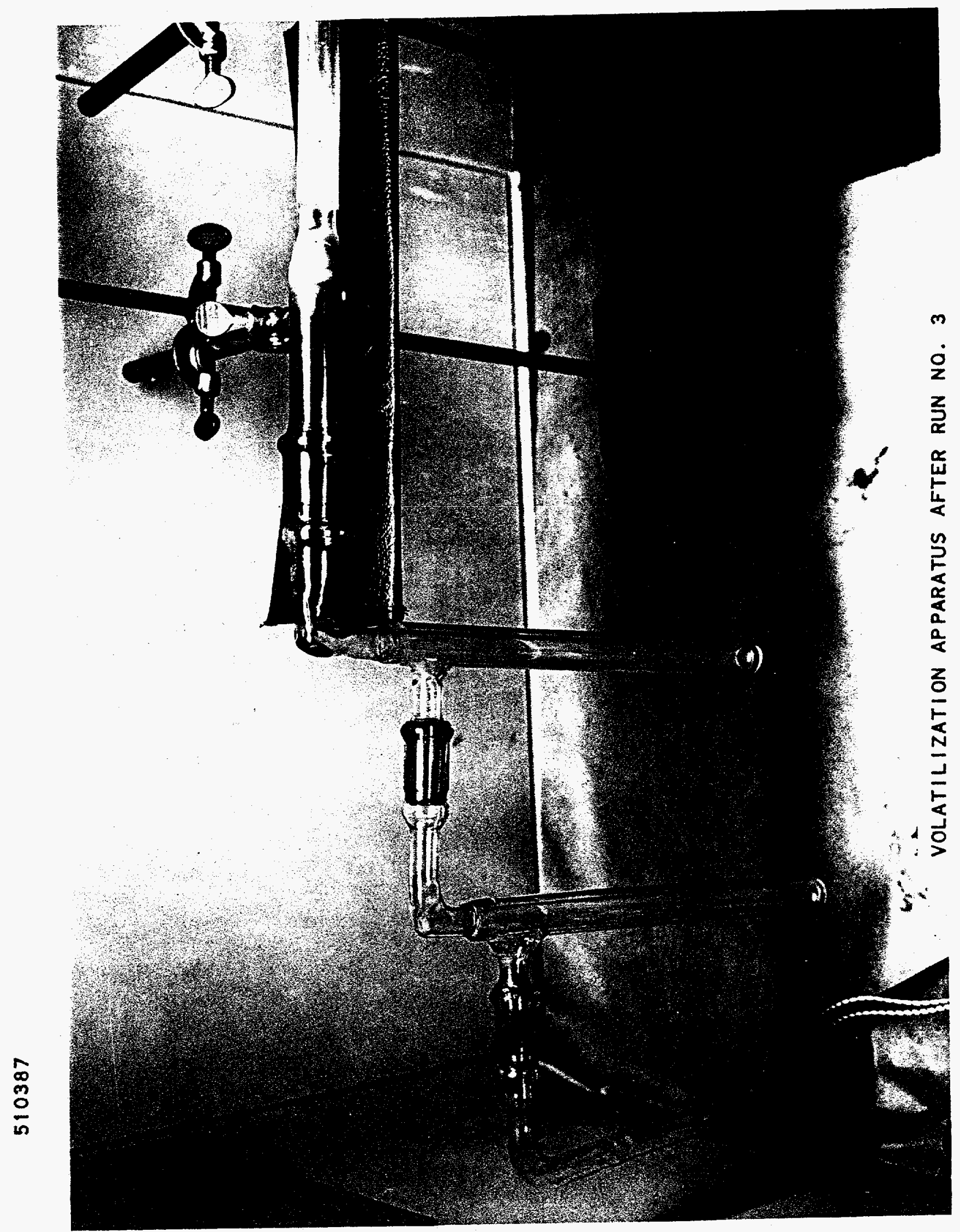

UNCLASS IF |ED 


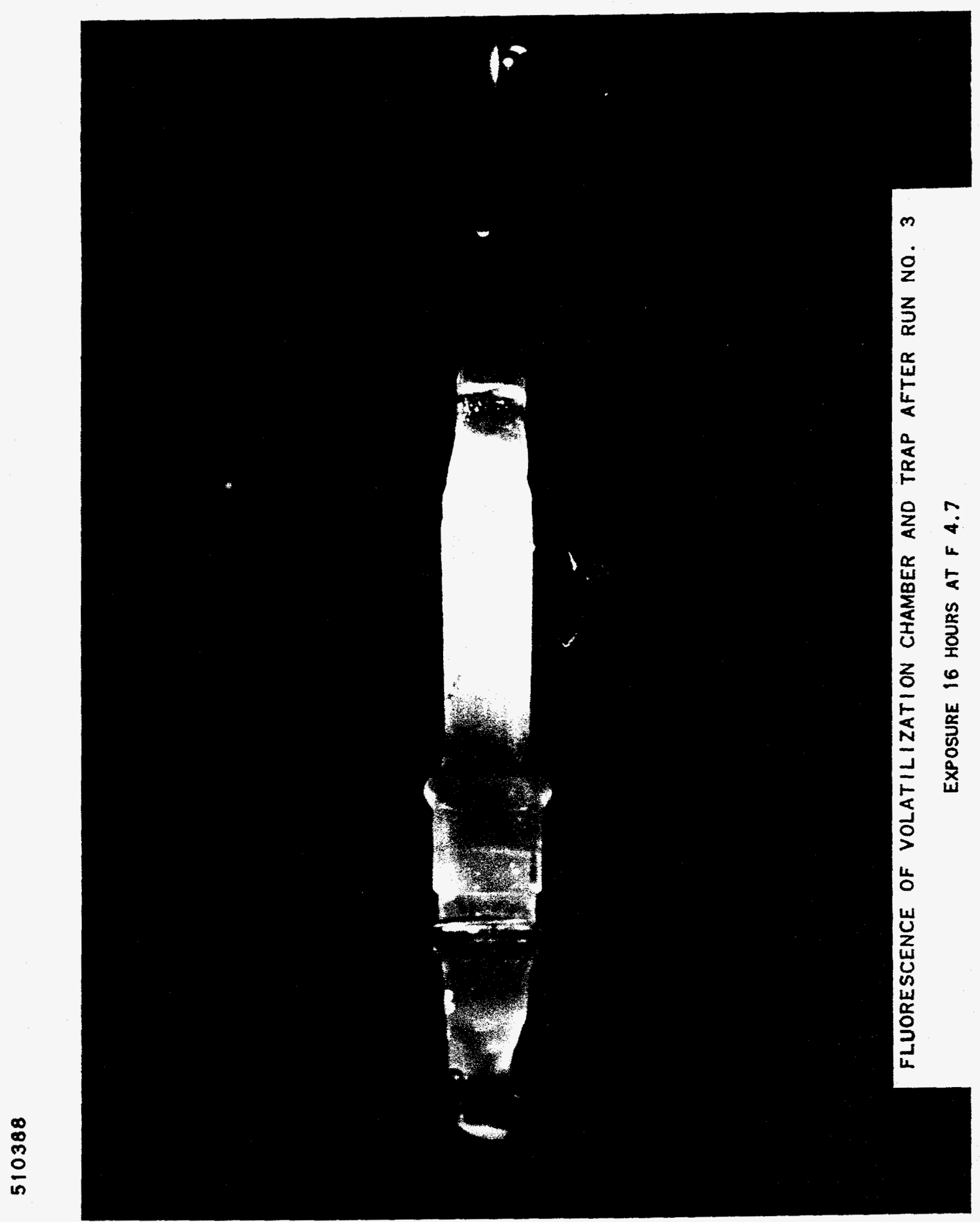

\section{UNCLASS IF IED}




\author{
Problem Title - Processing of Polonium-208 from Proton-Irradiated Bismuth \\ Report By - G. D. Nelson \\ Work Done By - G. L. Fox, H. W. Kirby, J. S. Kochendorfer, and G. D. Nelson
}

\title{
INTRODUCTION
}

A total of 57 millicuries of polonium-208, produced in the cak Ridge National Laboratory cyclotron, has been received at. Mound Laboratory. The polonium-208 is of interest because of its 2.93-year half life. (7.7 times that of polonium-210).

The purification of material from microcurie-level targets with tellurium as a carrier was described in the last report. The assay and concentration of alpha activity from 19 additional targets in the microcurie to millicurie range are discussed in this report.

\section{DETA ILED REPORT}

\section{Assay of Oak Ridge National Laboratory Targets 8 - 34}

Nineteen bismuth targets have been received from cak Ridge since early April. The targets contain all but 14 microcuries of the 57 millicuries of polonium-208 received through June 20 (Table I). ${ }^{1}$. Three of the samples $\left(8,9\right.$, and 10 ) were $13 / 4$ by $2 \frac{1}{8}$ inches, and the remainder were $2 \frac{1}{4}$ by 6 inches in surface area. All of the targets received were bombarded with the proton beam at grazing incidence, varying from 30 'degrees for Target 8 , 15 degrees for Target 9,7 degrees for Target 10 , to less than 7 degrees for Targets $11-34$.

The amount of alpha activity present in the surface of Targets 8 - 10 was determined with the alpha monitor. The surface of subsequent targets, which were all in the millicurie range, were too active to measure, but autoradiographs of them were made before chemical treatment (Figures 3 9).

Results of alpha and gamma assays of solutions of the bismuth and aluminum from Targets $8-34$ are given in Table II. The amount of radioactivity which was produced in each target is shown by Figure 1 .

The targets were weighed, and the aluminum was separated from Targets $8-15$, excepting Number 11 , by dissolution in dilute hydrochloric acid. The al uminum from Target 11. was dissolved from the bismuth with equal facility with sodium hydroxide-sodium nitrate solution. The bismuth was weighed after the aluminum was dissolved. The bismuth from Targets 13 and 15 was in many, smail, thin shreds collecting thẹse pieces for weighing was difficult. Nitric acid which does not attack aluminum but will dissolve bismuth, was used to dissolve the bismuth from the backing for Targets $16-34$. The weight of the bismuth was determined by difference for Targets $18:-34$ ( $i$ and $j$, Table II).

The bismuth was removed from Targets $16-25,30,34$ by dipping in nitric acid, followed by spraying with hydrochloric acid This procedure was repeated until the bismuth associated with the bismuth-aluminum bond was completely dissolved. During this procedure some aluminum was carried unavoidably with the bismuth solution, the amount depending on the weight of aluminum involved in the alloy forming the metal-to-metal bond. The bismuth from Target 29 seemingly dissolved readily:in:nitric acid alone, However, the alpha 
activity which remained in the aluminum portion of the target was high: ( $r$, Table.II), since some of the alloy containing alpha activity.evidently.remained invisible and was undissolved by the nitric acid.

Results of parallel-plate alpha counts made on the solutions of each target and its backing plate are given incolums $n$ and 0 , Table II. Only in the case of Target 22 was the alpha yield as great as the yield predicted from the electromagnetic data. ( $e$ and

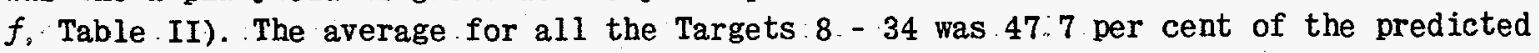
yield. The low-yield values are attributed to failure of all the beam to hit the target and to volatilization of polonium from the heated bismuth surface. If melting occurs, there is a good chance for the bismuth-aluminum alloy : to form.

Gamma counts were made on the solutions of the bismuth and the aluminum backing of each sample with a beta-shielded tube. These activities were compared to counts from a standard equilibrium radium solution at the same geometry to obtain the gamma values in microcuries given in. Columns $n^{\prime}$ and $0^{\prime}$, Table. II.

Polonium was concentrated from solution prior to purification by electrochemical deposition on bismuth powder. The values in Column in the table for each of the targets is the amount of alpha activity which was not electrochemically:deposited after treating the 50 -milliliter solution of the target bismuth with 1.5 grams of powder. The per cent of the value in Column $n$ which was concentrated is given in Column: $s$, Table:II.

\section{DISCUSS ION}

\section{Bismuth-Aluminum Alloy : Formation}

From the autoradiographs (Figures $3-9$ ) it may be seen that certain areas of the targets appear melted (Targets 20 and 21. for example). From the weight of bismuth and the area of the targets it was estimated that the bismuth had an average thickness of 0.003 inch. Even with 0.003 inch of bismuth, its heat transfer was poor, and the heat generated by the proton beam was sufficiently great to cause melting with subsequent alloy formation between the bismuth and the aluminum backing.

Any appreciable amount of alloying of bismuth and aluminum should be avoided if at all possible. If the aluminum gets to the surface of the target, the polonium 208 yield decreases because bismuth is not being irradiated. At the same time the gamma activity increases because of the proton irradiation of the impurities in the aluminum. ${ }^{2}$. high gamma yield is also to be avoided because of health considerations. The data plotted in.Figure 2 represent the amount of gamma :activity which would appear in targets of 100 millicuries of alpha activity if an amount of gammactivity proportional to that in Targets 8 - 34 were present For Target 15 , for example, 38 millicuries of gamma actipity would be produced if 100 millicuries of polonium-208 were produced.

From the processing standpoint any aluminum in the bismuth chloride solution is objectionable because it retards the passage of the solution through filters and bismuthpowder beds used to concentrate the polonium, Also, any iron impurity carried with the al uminum into the bismuth chloride solution is objectional because ferric chloride attacks the bismuth and Iowers the amount of polonium which is effectively concentrated. Processing difficulties with the bismuth solutions of the target bismuth containing aluminum are borne out in the lower percentage concentrated : $(s$, Table II) for Targets $20-23$.

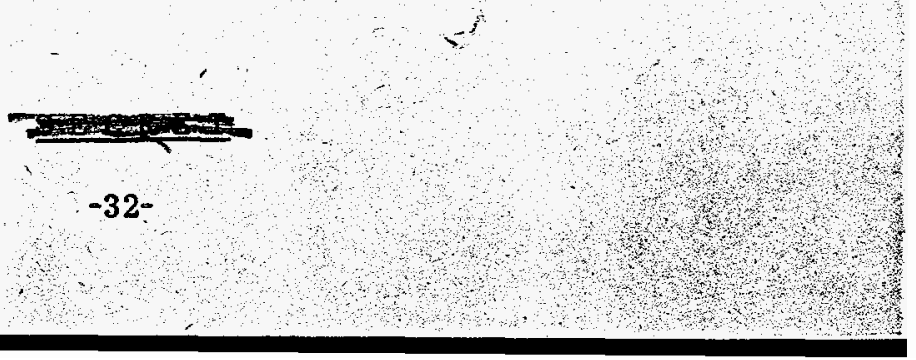


The problem of bonding bismuth to aluminum has received attention by the Electromagnetic Research Division of Oak Ridge National Laboratory. In an effort to minimize the amount of aluminum near the surface, they have been making the aluminum-bismuth bond by first wetting the aluminum with bismuth and wiping off the excess aluminum-rich bismuth. Then, fresh bismuth is spread over the heated aluminum (like lipstick is spread) until.the aluminum is covered. The bismuth is then machined to the desired thickness for bombardment. ${ }^{3}$

Some thought has been given to the possible use of purer aluminum in the backing material ${ }^{2}$ or the use of 8.6 per cent nickel-bismuth as target material to reduce the gamma activity present during processing. The melting point of this nickel-bismuth alloy is $470^{\circ} \mathrm{C}$. and may possibly have a higher heat conductivity than bismuth alone. The higher melting point should make higher beam currents possible. The copper isotopes produced by proton reactions on nickel are all of short half life and would cause no health hazard when processing. However, if high-alpha-yield targets are produced with bismuth diluted with nickel, the short-half-life gamma activity would have to decay before the targets could be handled for shipping and processing.

\section{CONCLUSIONS}

Targets containing up to 20.5 millicuries of polonium-208 have been prepared by the oak Ridge cyclotron. A total of 57 millicuries have been produced, The gamma activity in the targets represents as much as 24 per cent of the total activity present one week after bombardment. It would be desirable to minimize the degree of alloying between the aluminum and the bismuth of the targets to lower the gamma activity and to simplify processing of the targets. The use of pure aluminum as a backing material or, if practical, the use of a nickel-bismath alloy as a target material may decrease the gamma activity of the targets.

\section{REFERENCES}

1. Fox, G. L. and Nelson; G. D。 Rpt. Gen, Res., MLM-559, p. 5, May 12, 1951 .

2. Nelson, G。: D. This Volume, p. 6 .

3. Stetsen, N. Private Communication. 


\section{TABLE :}

POLONIUM-208 RECEIVED FROM OAK RIDGE NATIONAL LABORATORY THROUGH $6 / 20 / 51$

TARGETS

TARGETS

TOTAL BY INDIVIDUAL TARGET ASSAY
MILLICURIES

$$
\begin{aligned}
& \text { 4. } 6 \text { (REPORTED LAST QUARTER) } \\
& \text { 8. - } 34
\end{aligned}
$$

0.020

56.97

56.99 
TABLE . II

CHARACTERISTICS OF ORNL TARGETS 8 - 34

Column

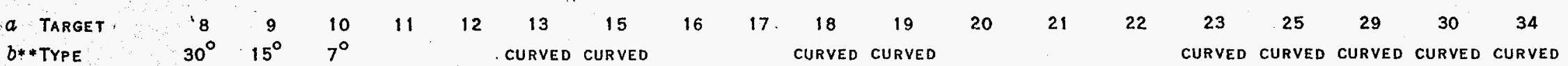

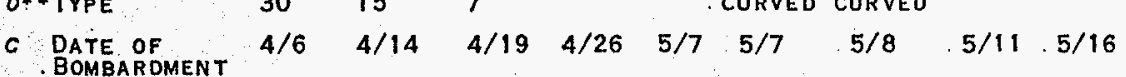

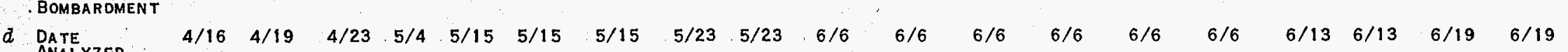

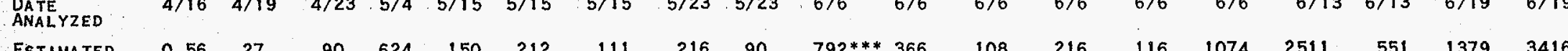

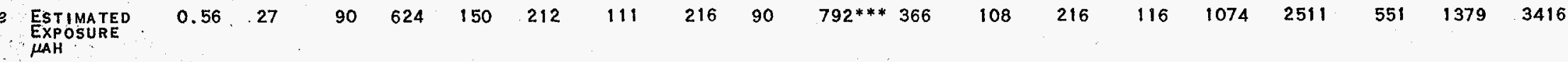

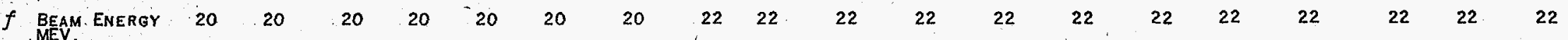

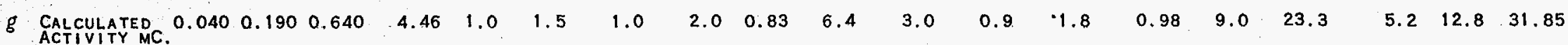

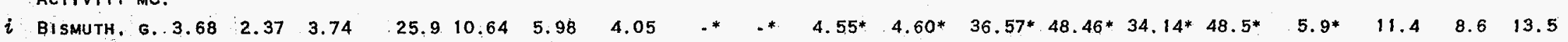

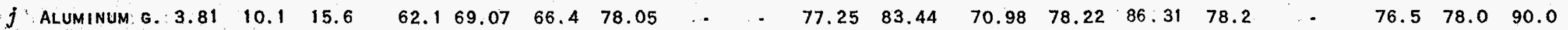

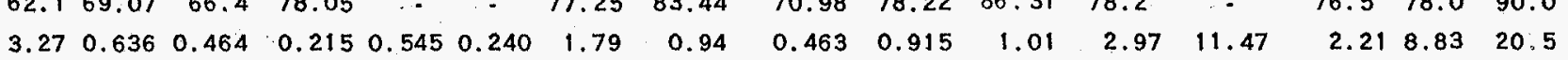

ALPHA ASSAY $0.016 \quad 0.1040 .283$ OF BISMUTH

$\begin{array}{lllll}n ' \text { GAMMA ASSAY } & 0.02 & 0.59 & 2.97\end{array}$ OF BISMUTH

- Alpha Assay $0.01 \quad 7.52 \quad 0.11$ OF ALUMINUM

$14.8 \quad 15.21 .5 .36$

$\begin{array}{llll}13.83 & 23.43 \quad 2.24 \quad 26.1\end{array}$

17.2

$: 3.40 \quad 5.63$

$2.26 \quad 102.3 \quad 162.0$

$11.2 \quad 42.6 \quad 131.0$

D' Gamma Assay $0.46 \quad 4.09 \quad 13.2$ OE ALUMINUM

$\begin{array}{llll}1.52 & 0.13 & 0.63\end{array}$

$\begin{array}{llll}1.28 & 1.64 & 1.35 & 1.67\end{array}$

$2.65 \quad 1.22 \quad 5.5$

$16.7 \quad 13.2 \quad 12.9$

政

SUCLBNATANT $\mu \mathrm{C}$

q. Per CenT OF 40.0 .54 .7 $\begin{array}{llll}\text { THEORETTCAL } & 40.0 & 54.7 & 44.2\end{array}$ Y $(N, G$ G 100$)$

$\begin{array}{llll}r \text { PER CENT OF } & 0.1 & 0.07 & 0.04\end{array}$ ALPHA ITY IN ALUMINUM

$\begin{array}{lllllllll}5.08 & 17.65 & 123.0 & 68.54 & 11.9 & 6.01 & 109.9 & 65.4\end{array}$

$4.73 \quad 9.90$

$2.58 .266 .5 \quad 364.0$

115.0374 .8311 .2

PER CENT CONCENTRATE
ON BISMUTH POWDER (1.P/N)

\section{$\begin{array}{lllllllll}1.4 & 6.48 & 1.01 & 0.34 & 3.15 & 1.0 & 5.2 & 6.2\end{array}$}

32. 311.5

45.2120 .5

10.9

$\begin{array}{lll}4.06 & 24.7 & 3.87\end{array}$

$\begin{array}{lllllllll}73.3 & 63.6 & 30.9 & 21.5 & 27.3 & 28.9 & 28.0 & 31.3\end{array}$

$51.4 \quad 50.8$

$103.0 \quad 33.0 \quad 49.3$

$42.6 \quad 69.0 \quad 64.4$

$\begin{array}{llllllll}0.04 & 0.02 & 0.10 & 0.07 & 0.03 & 0.13 & 0.07 & 0.20\end{array}$

$0.30 \quad 0.20$

$0.30 \quad 0.04 \quad 0.05$

$0.8 \quad 0.15 \quad 0.06$

Contains some Aluminum

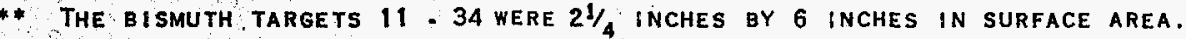

*** BOMBARded 144 MICROAMPERE hOURS AT 20 MEV. 

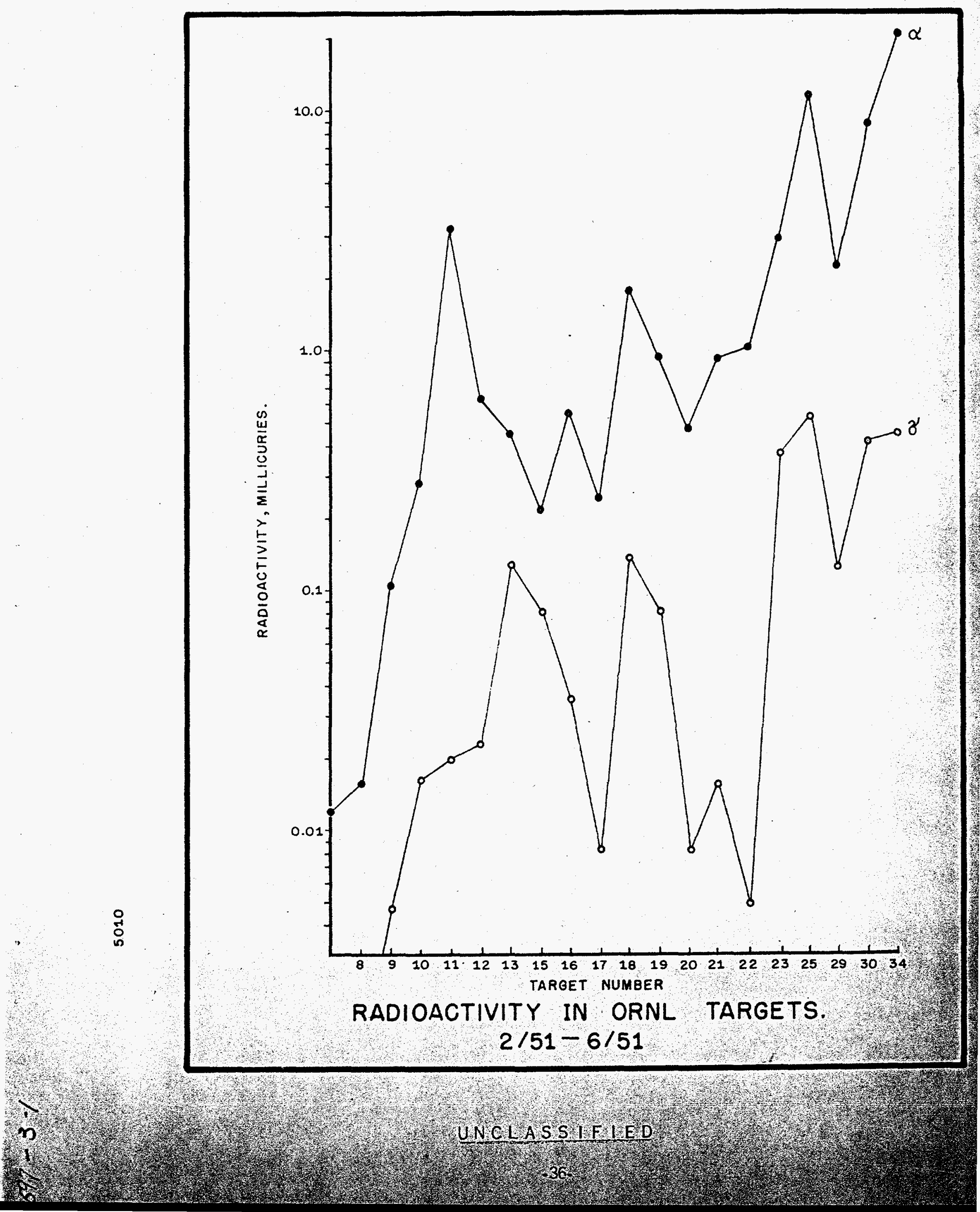


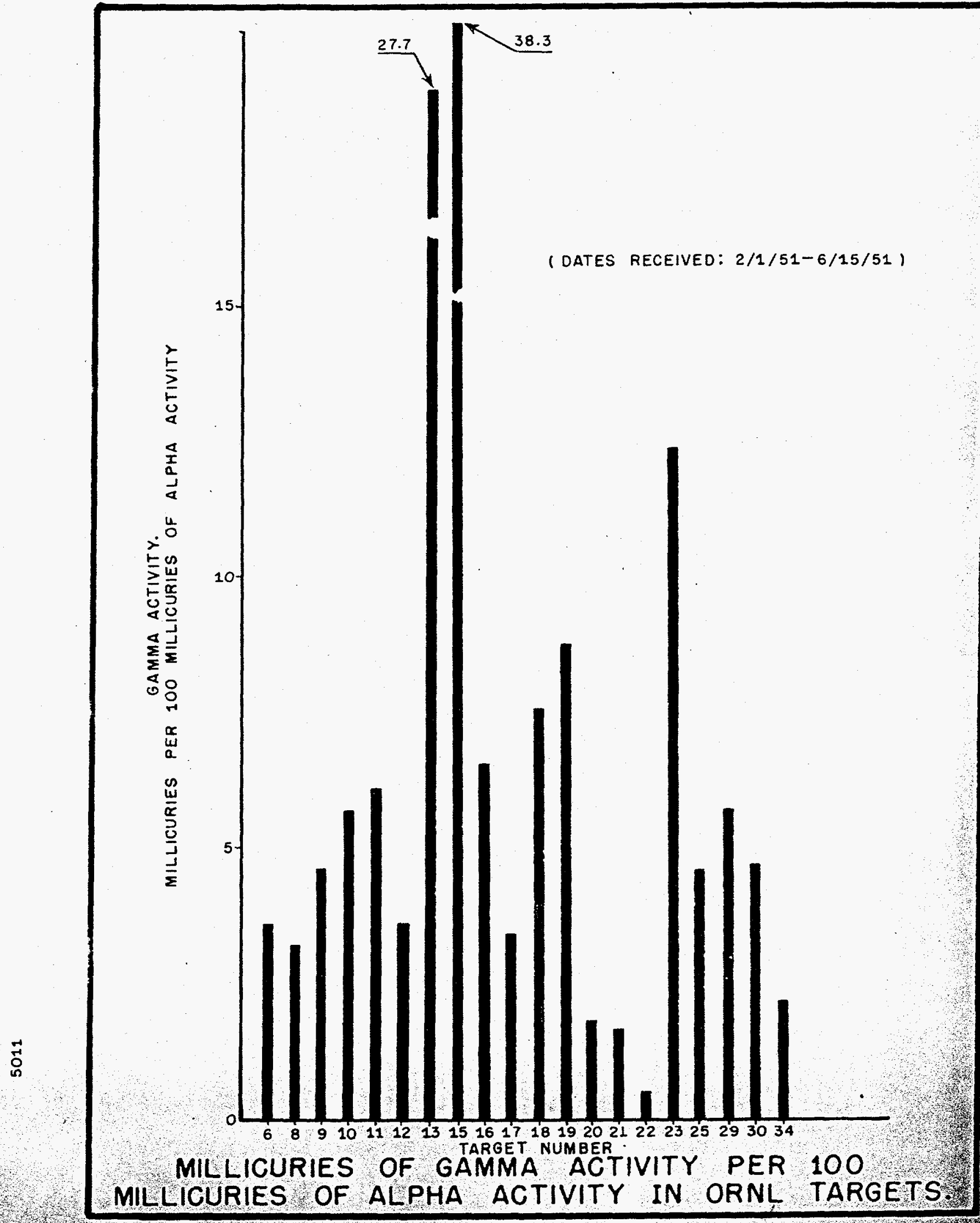


(10 MINUTE EXPOSURES: NUCLEAR TRACK EMULSION)

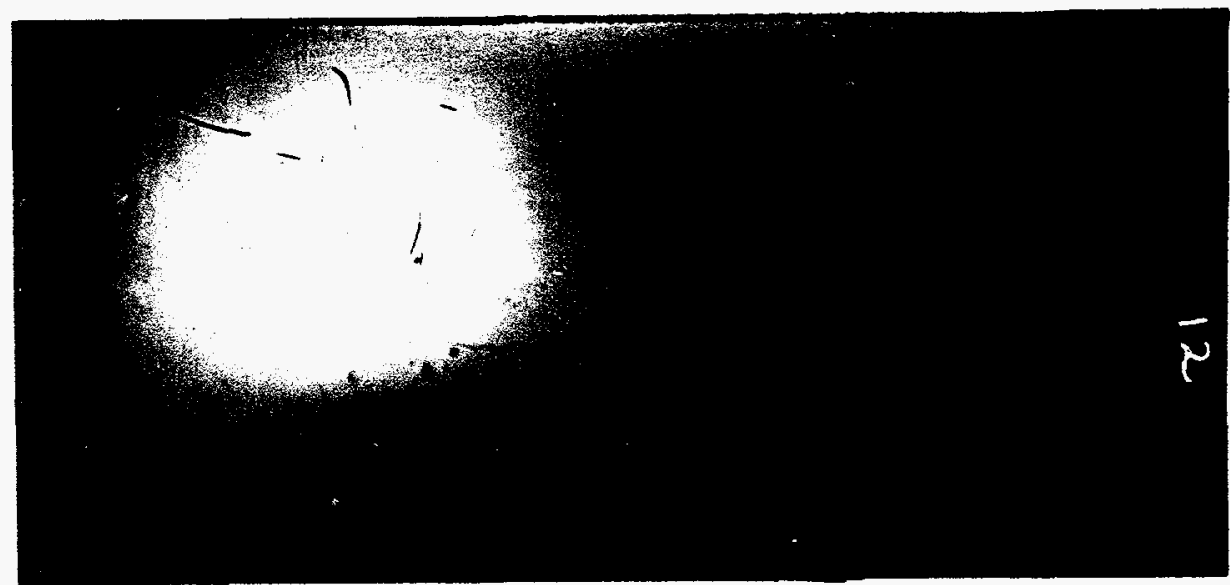

TARGET NUMBER 12.

BEAM DIRECTION

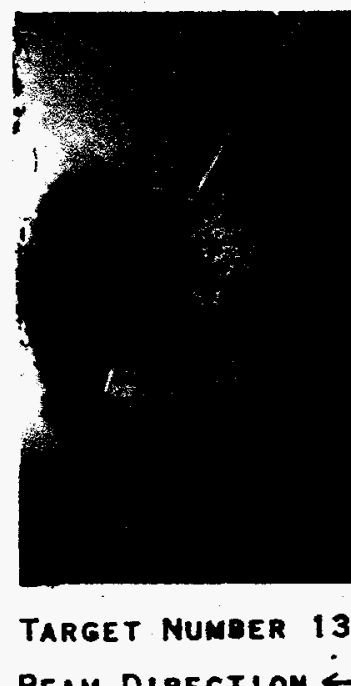

BEAM DIRECTION

Pan

. 


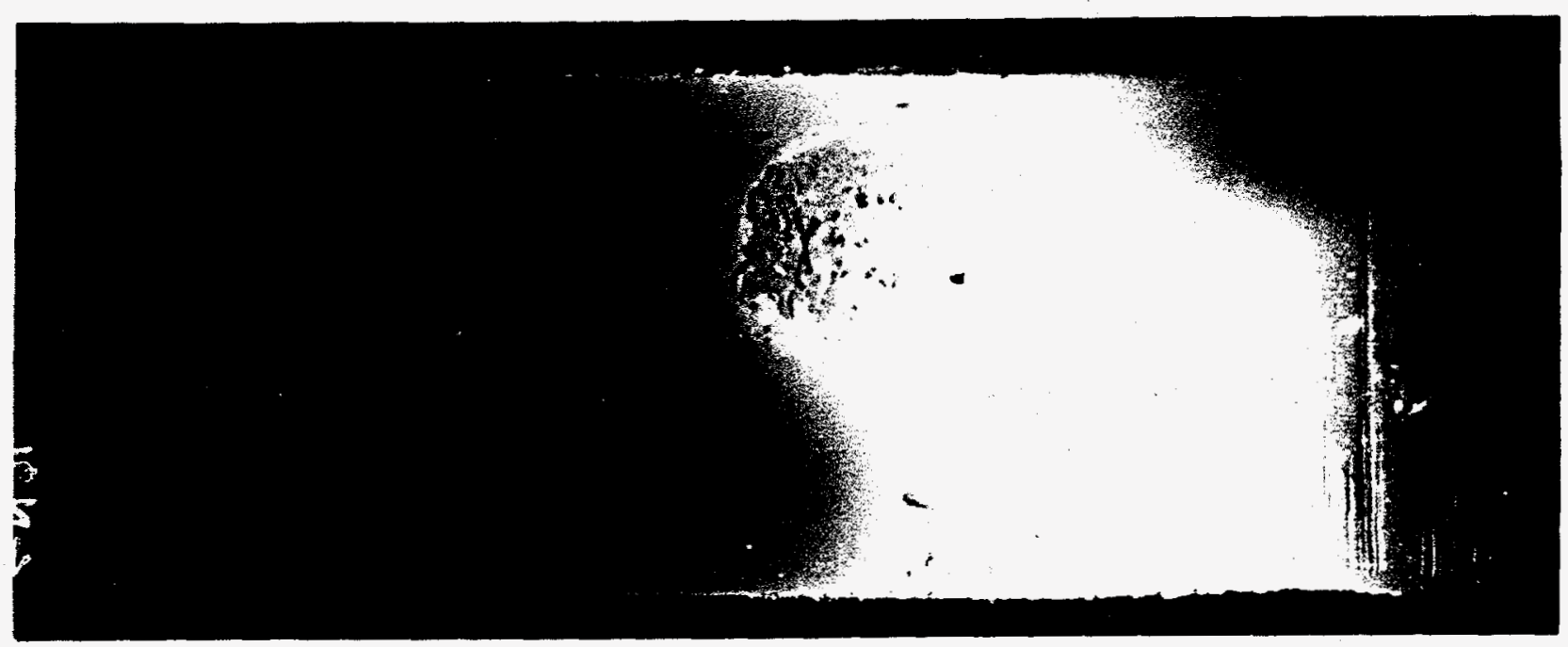

TARGET NUMBER 16

BEAM DIRECTION $\rightarrow$
22 MEY.

216 нAн.
$0.545 M C$.

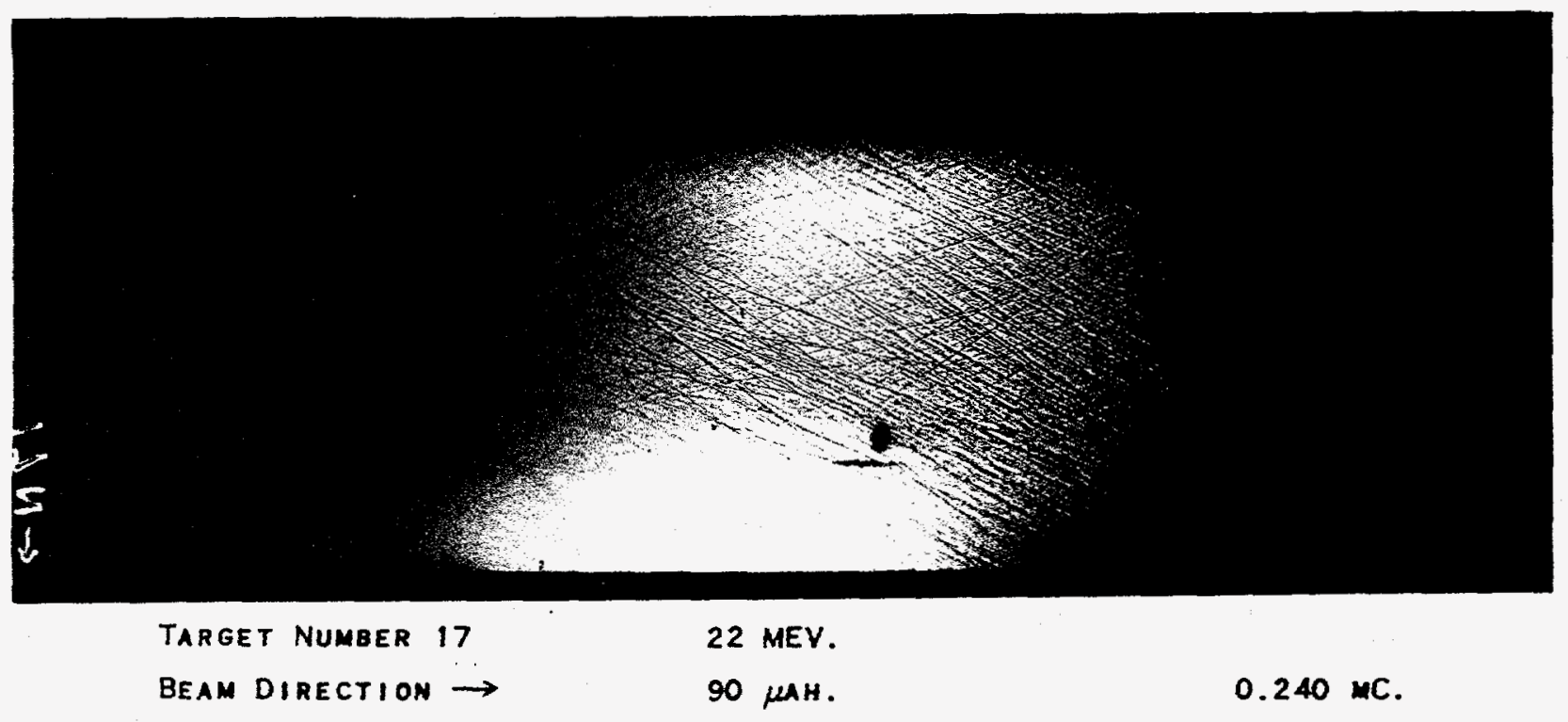

UNCLASSIFIED

.39 


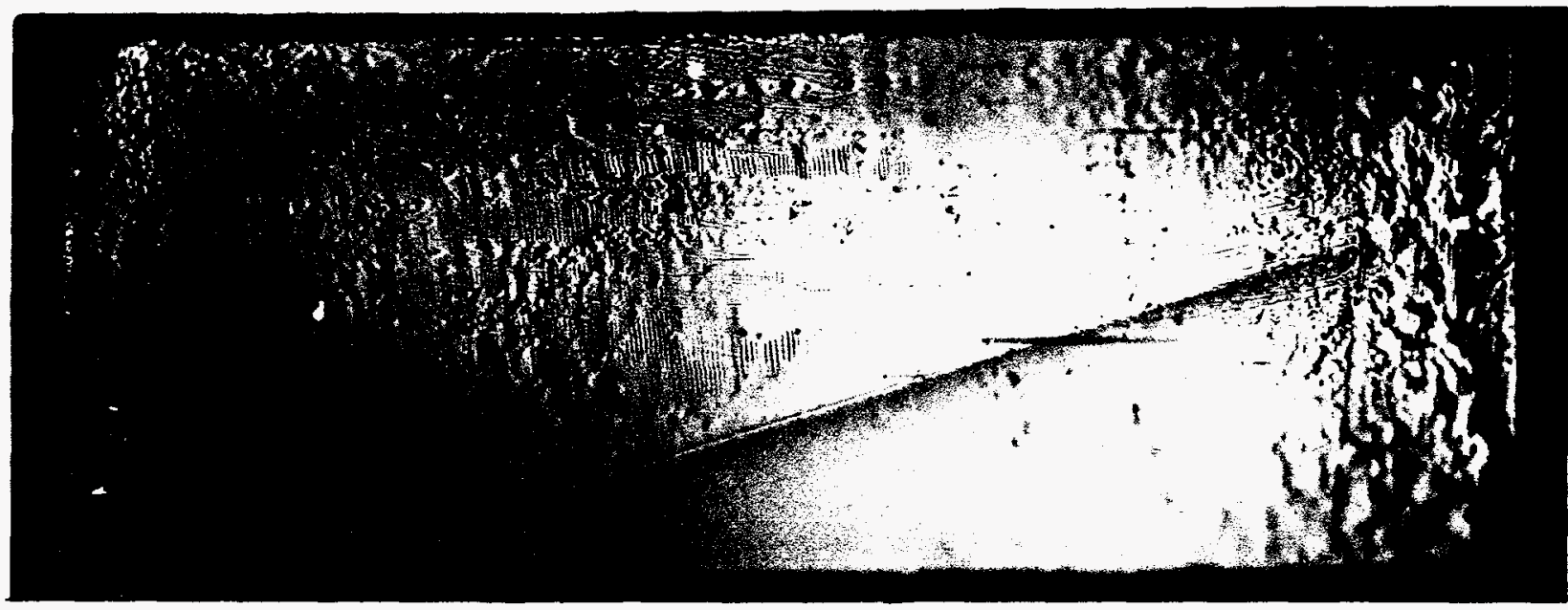

TARGET NUMBER 18

BEAM DIRECTION $\rightarrow$
648 MAH. AT 22 MEV.

144 НАH. AT 20 MEV.
$1.79 \mathrm{MC}$.

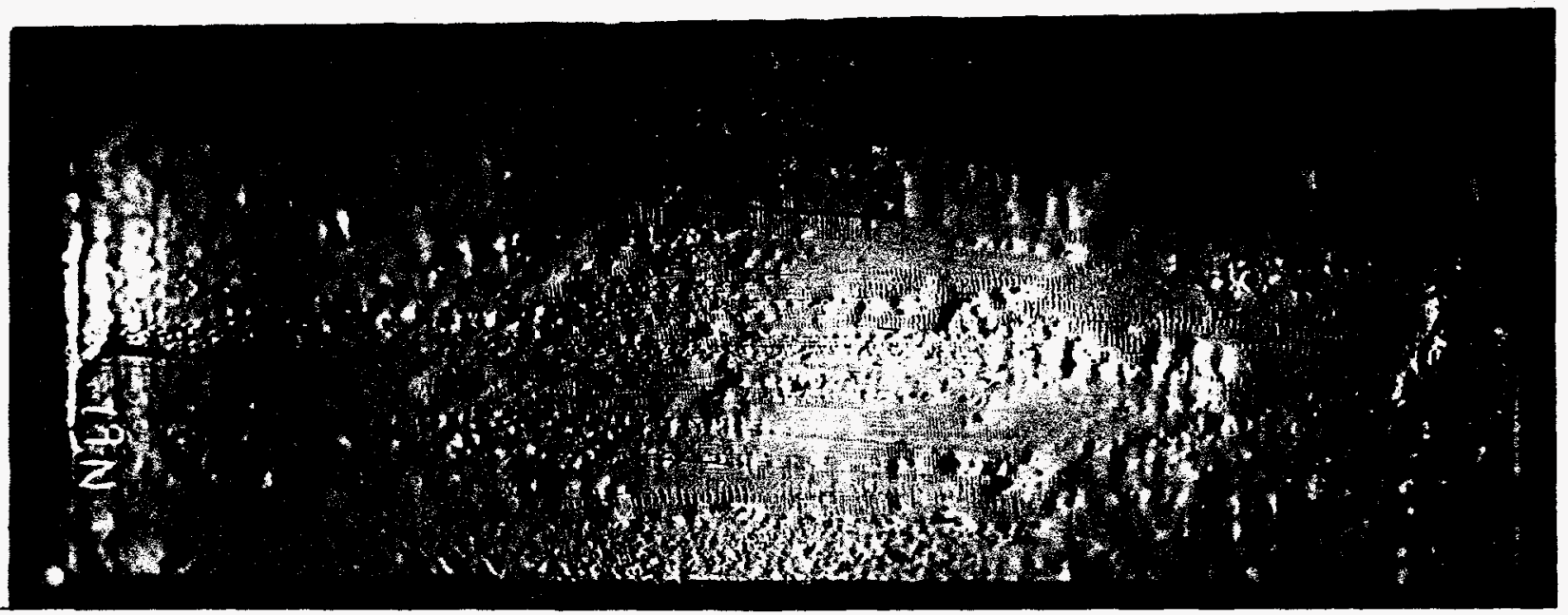

TARGET NUMBER 19

BEAM DIRECTION $\rightarrow$
22 MEV.

366 нАн.

$0.94 m C$. 


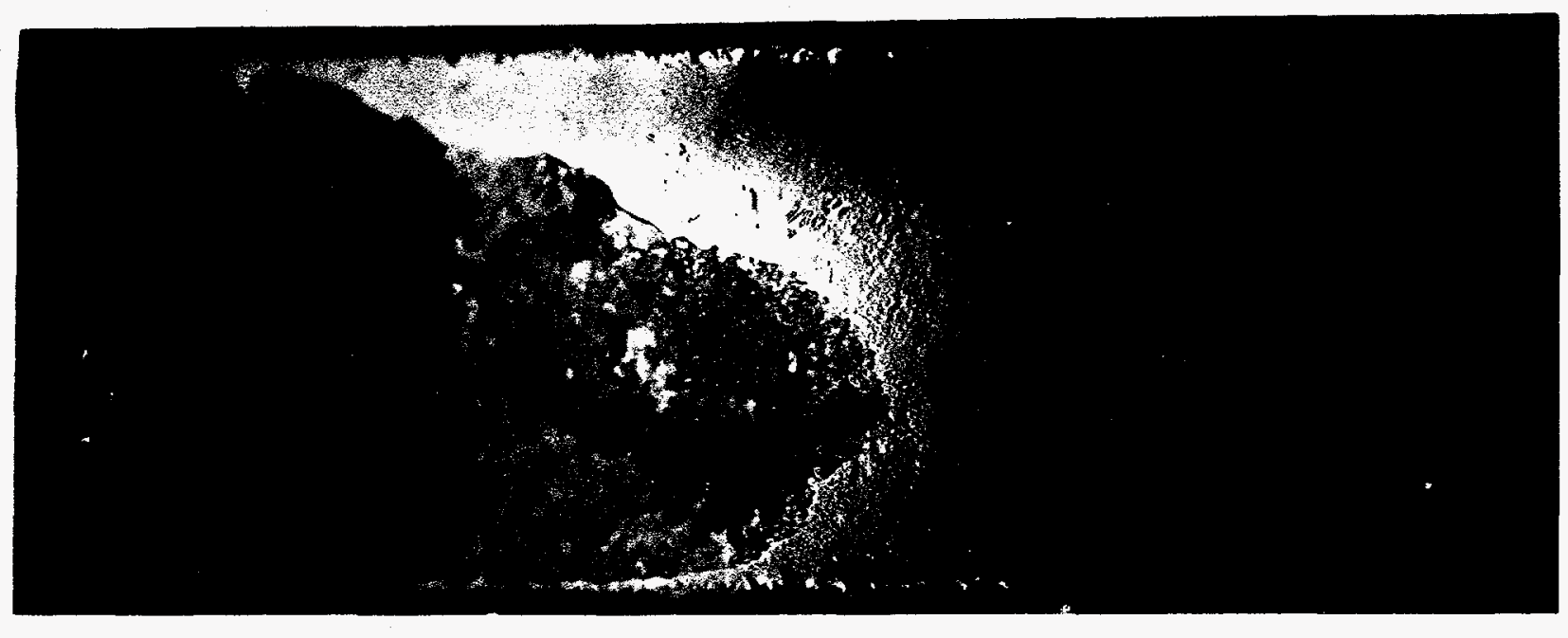

TARGET NUMBER 20

BEAM DIRECTION $\uparrow$
22 MEV.

$108 \mathrm{\mu AH}$.
$0.463 M C$.

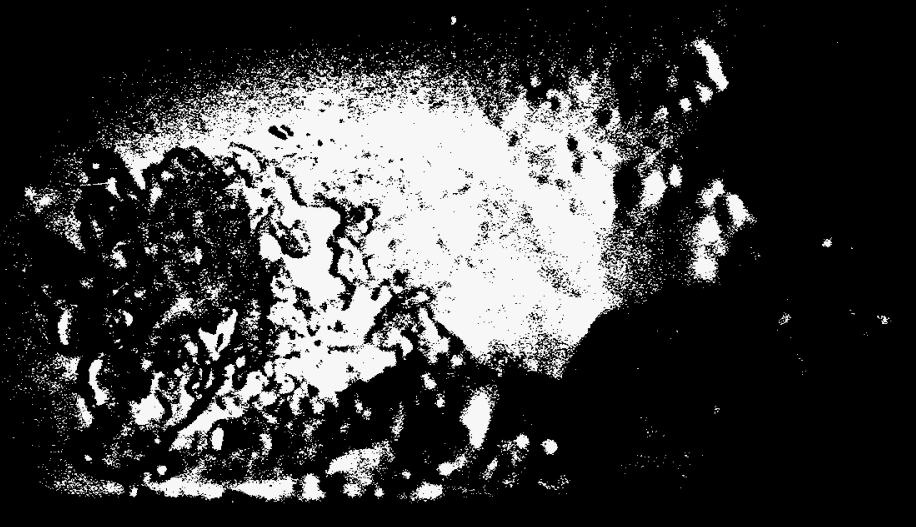

TARGET NUMBER 21

BEAM DIRECTION $\uparrow$
22 MEY.

216 нан.
0.915 m.

UNCLASS IF IED 
( 10 MINUTE EXPOSURES. DUPLITIZED X-RAY FILM)

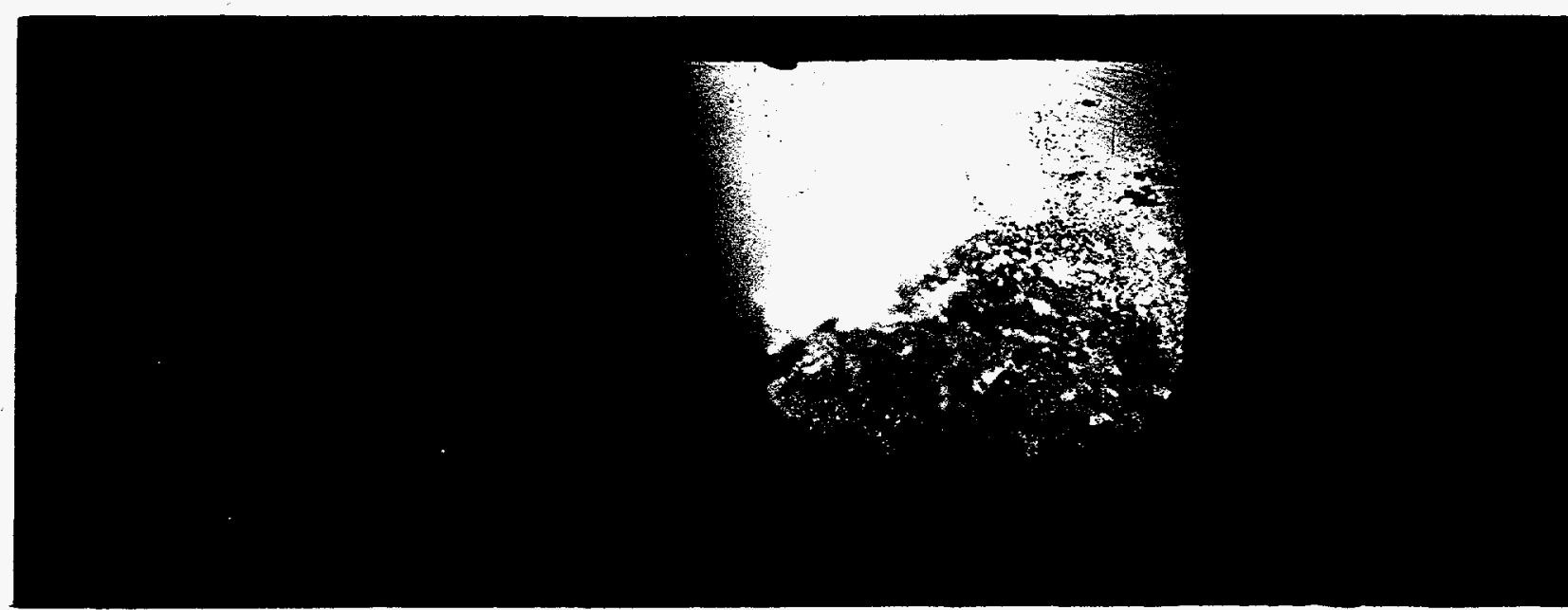

TARGET NUMBER 22

BEAM DIRECTION $\uparrow$
22 MEV.

116 رAH.
$1.01 \mathrm{MC}$.

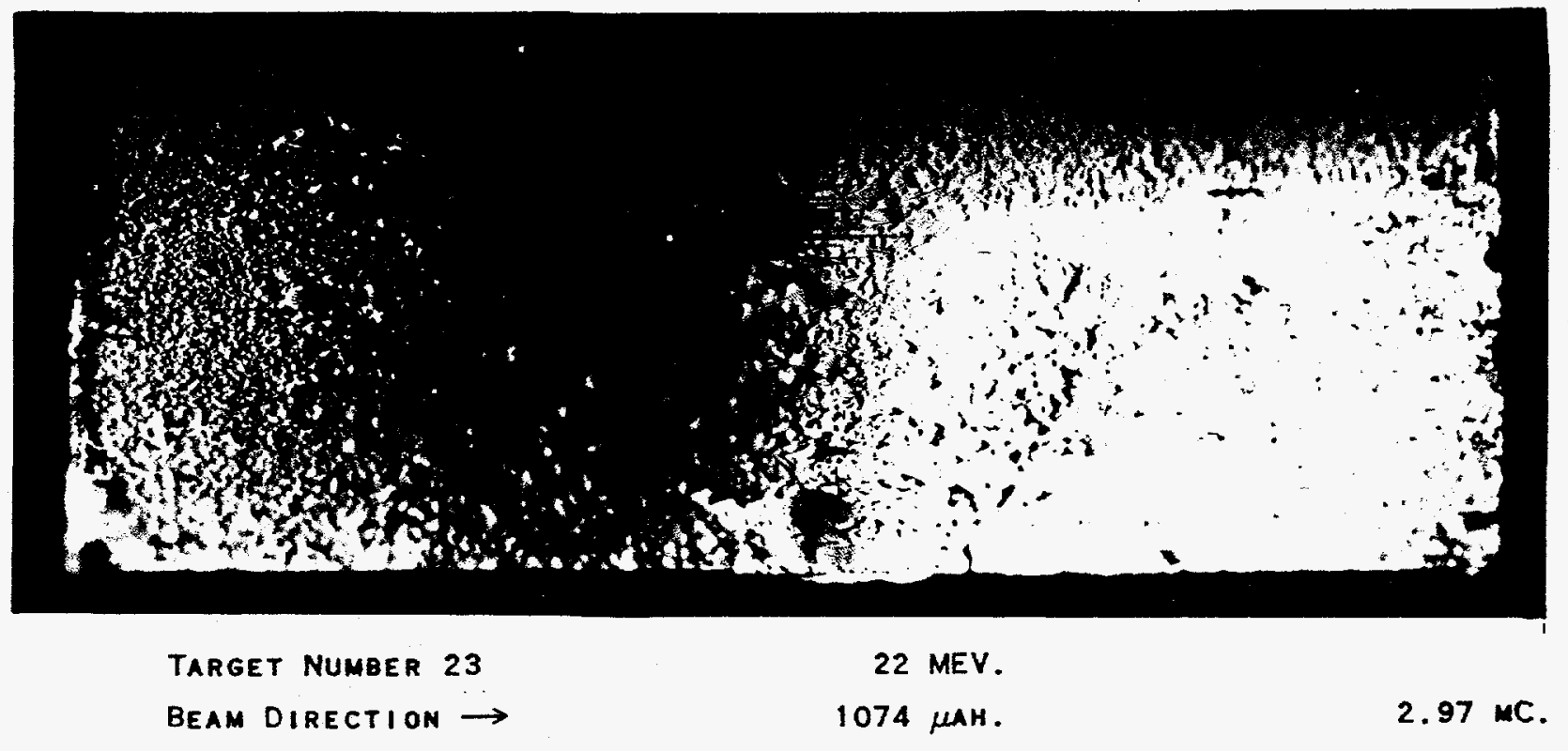

UNCLASS IF IED 


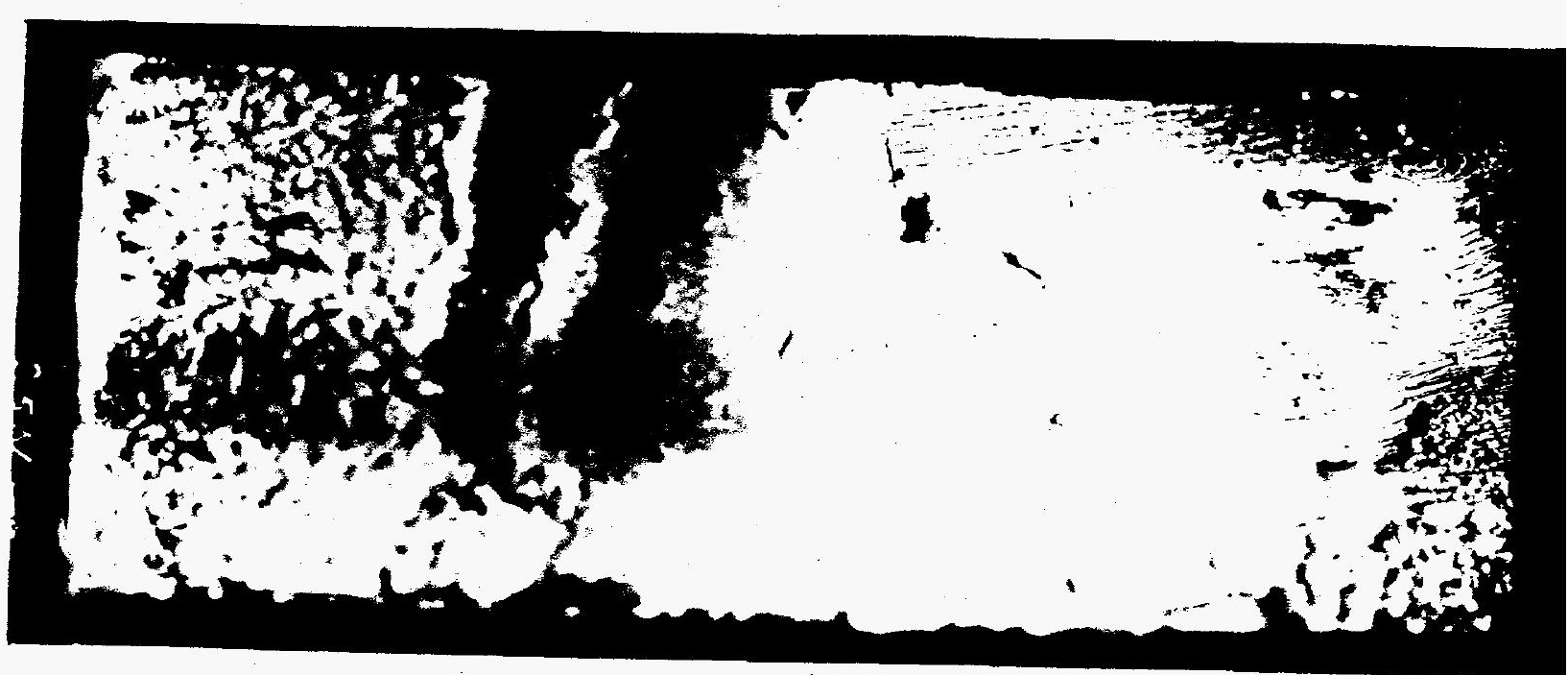

TARget Number 25 22 MEV.

BEAM DIRECTION $\rightarrow$

2511 HAH.

$11.47 \mathrm{MC}$.

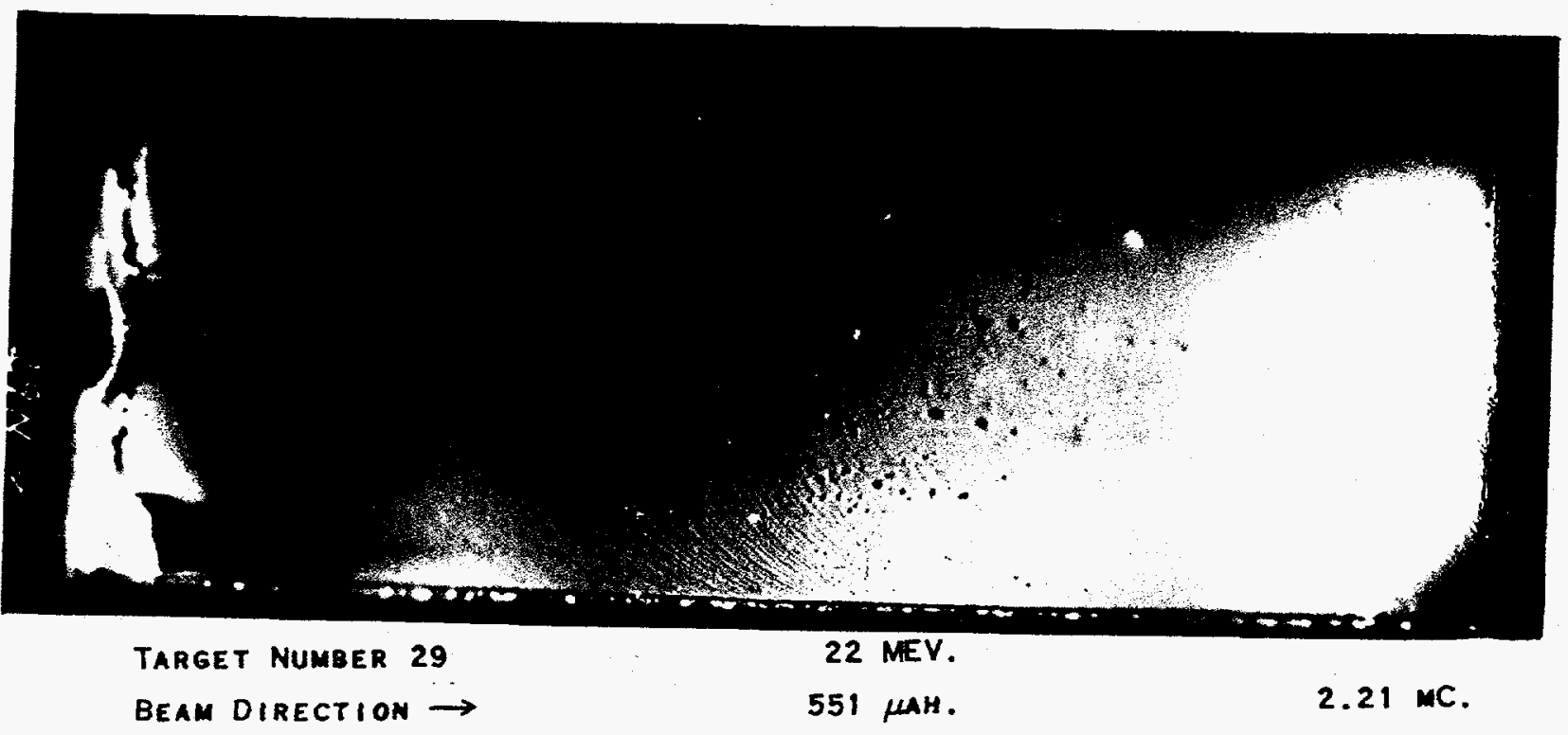




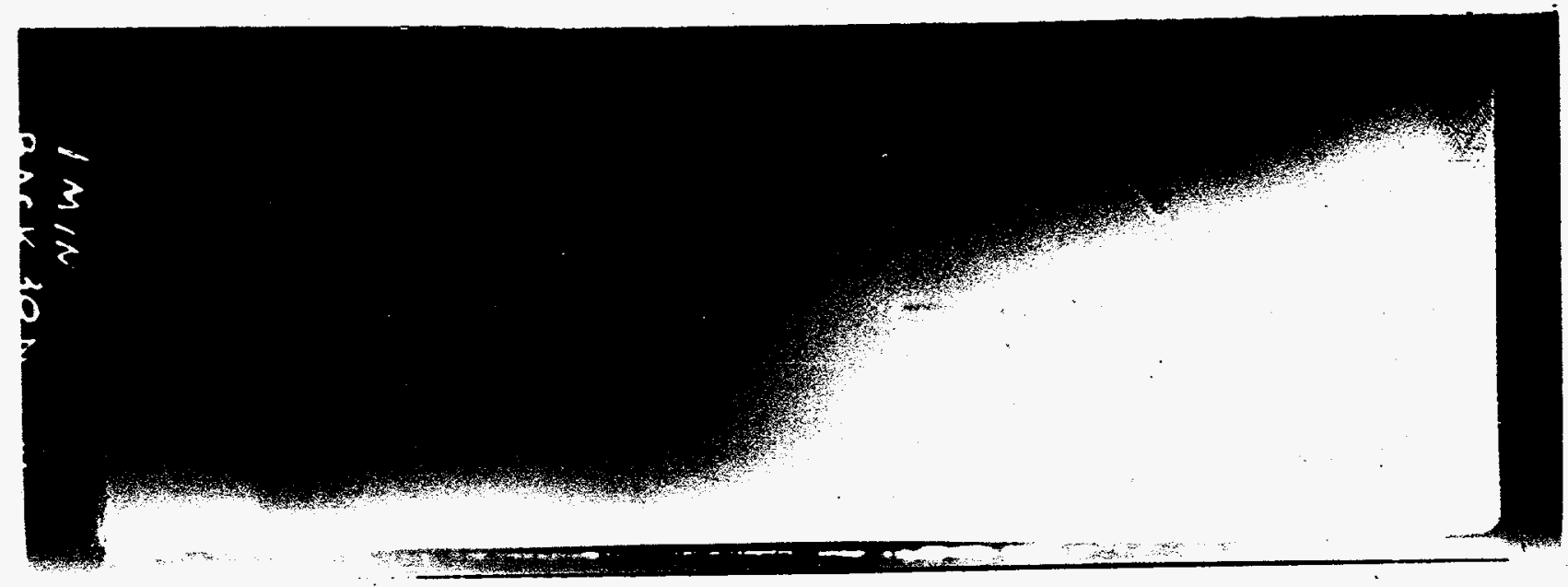

TARGET NUMBer 30 22 MEV.

BEAM DIRECTION $\rightarrow$

1379 НАH.

$8.83 \mathrm{MC}$.

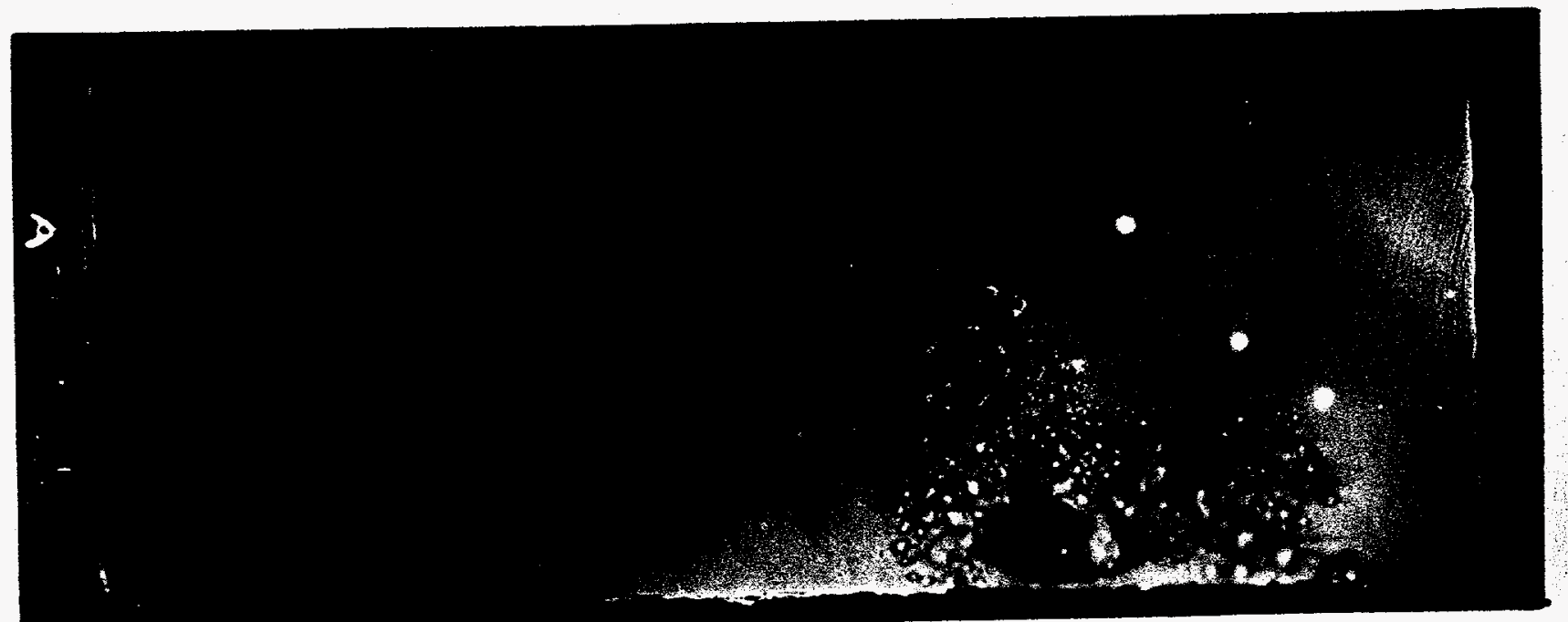

TARGET NUMBER 34

BEAM DIRECTION $\rightarrow$
22 MEV.

3416 щан. $\therefore \quad 20.5 M C$.

UNCLASSIF|ED

.44 . 
Problem Title - Diffusion of Poloniun in.Bismuth. Through Aluminum

Report By - J.B. Otto, Jr. and W. H. Poner

Work Done By - J. B. otto, Jr.

\section{INTRODUCT ION}

Aluminum has been suggested as a protective coating material for bismuth targets during proton irradiation to produce polonium-208 in the cyclotron or linear accelerator. Gross loss of polonium in the accelerators or adjacent areas would create a serious contamination problem. Hence, the rate of diffusion of polonium through.a thin aluminum cover of a bismuth-polonium disk is being studied. ${ }^{1}$

\section{DETAILED REPORT}

\section{Preparation of the Sample}

A sample holder was constructed (Figure 1): to permit the preparation of a bismuthpolonium sample whose activity could escape only through a thin aluminum cover foil. A 0.001 -inch-thick aluminum foil was mounted between aluminum rings. (Assembly, E, Figare 1). Cover, $F$, was placed under the assembly to prevent contamination of the outside of the foil or the outside of the assembly during casting. The assembly was heated on a hot plate to the melting temperature of bismuth. Molten metal containing 6.96 millicuries of polonium per gram of bismuth was then poured on the foil. Flat bismuth surfaces on the under side next to the aluminum foil were obtained only if the bismuth was cast $1 / 4$ inch thick or more. The assembly was tapped on the hot plate to remove air bubbles, and the casting and assembly were cooled. Cover plate, $G$, and gasket, $H$, were fastened to $r i n g, A$, to prevent loss of polonium from the slug by routes other than through the aluminum foil.

\section{Distribution of : Polonium}

A count of 50,500 disintegrations per minute was obtained on the outer surface of the aluminum foil immediately after preparation of the sample. No contamination was noticed on the sides or cover plate of the sample holder, or on the inside surface of the plug placed adjacent to the outside of the aluminum foil. A straggling curve of the activity coming through: the aluminum foil was run to determine the depth and distribution of the polonium beneath the surface of the foil ${ }^{2}$ : (Figure 2). The distribution of polonium. in the aluminum foil immediately after casting the bismuth-polonium slug is approximately uniform throughout the range of the polonium below the surface of the foil.

straggling curves were run after heating the samples for $16 ; 54$, and 196 hours at $200^{\circ} \mathrm{C}$. (Figure 2). The surface count decreased slightly with the heating, but the total count (at zero pressure) increased with increased heating time. ApparentIy polonium was diffusing slowly into the lower depths of the aluminum foil but was being volatilized from the surface at a rate slightly more rapid than its diffusion into the surface layer.

Autoradiographs were taken of the surface of the one-mil aluminum foil after the assembly had been heated for 196 hours at $200^{\circ} \mathrm{C}$. Exposures were made on Eastman Nuclear Track Film cut in a one-inch circle and pressed against the aluminum surface. Exposures of 3 and 17 . hours both showed activity centers (Figure 4). Two major spots can be seen 
on the autoradiographs as well as a number of smaller spots. No pores in the aluminum foil were visible before the run when the foils were examined in.a darkened room with the aid of a light-tight box. The foil must have had invisible microscopic defects to permit polonium to penetrate the foil in the manner indicated by the autoradiographs and the straggling curves.

The one-mil aluminum foiliwas peeled from the bismuth-polonium surface, and a count of $3.6 \times 10^{7}$ disintegrations per minute was obtained from the under side. The:shape of the straggling curve for the under side of the foil. (Figure 3 ) is typical of curves obtained for a thin sample. Practically.all of the counts on the under side of the aluminum. foil. were from polonium lying on the aluminum surface. The polonium-bismuth surface, after the one-mil aluminum foil had been removed, had an activity of $3.85 \times 10^{8}$ disintegrations per minute. The one-mil aluminum foil had effectively prevented the spread of polonium fron the bismuthpolonium surface.

\section{REFERENCES}

1. Otto, J. B., Jr., Rpt. Gen. Res., MLM-559, p. 21, May 21, 1951.

2. Nelson, G. D., Rpt. Gen。 Res., MLM-559, p. 16, May .21, 1951. 


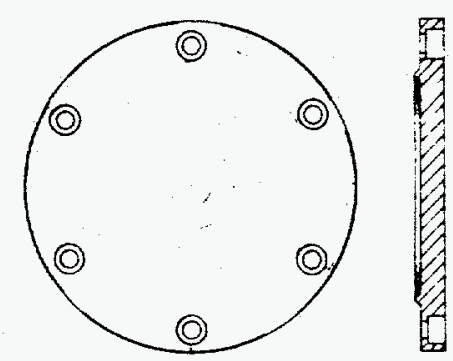

"G" cover plate

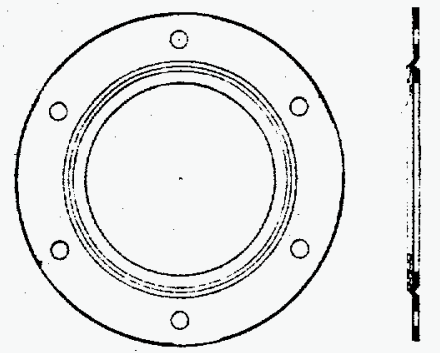

"H" GOPPER GASKET

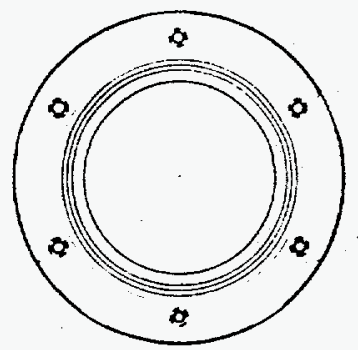

"A" RING
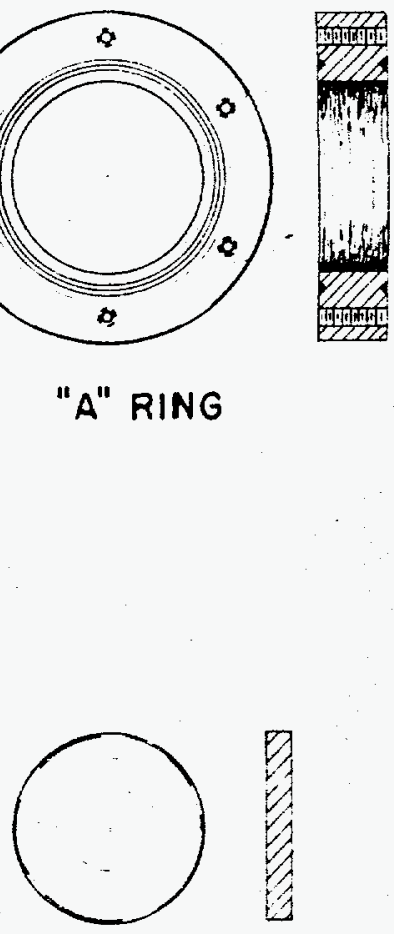

"D" PLUG

"C" RING

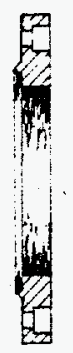

"G" cover plate

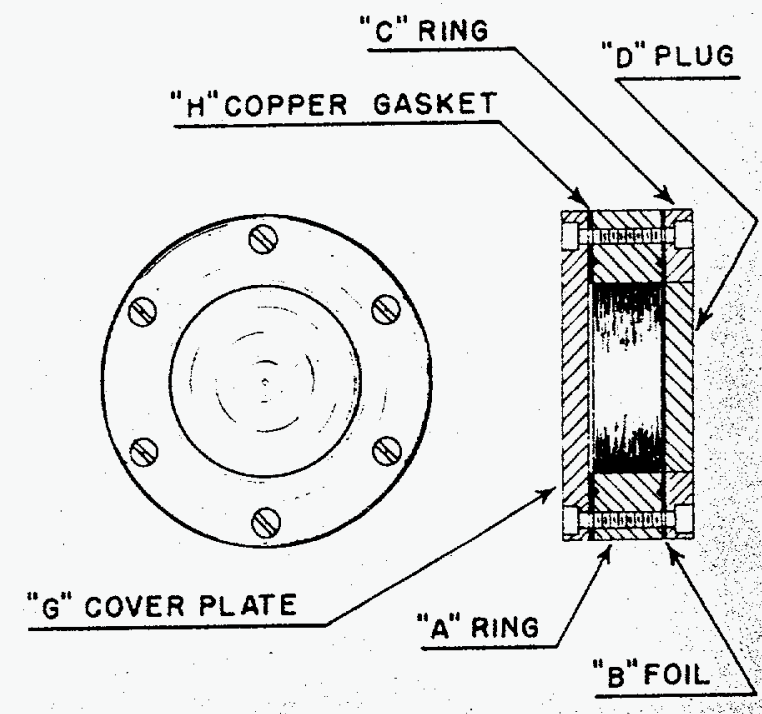

"D" PLUG
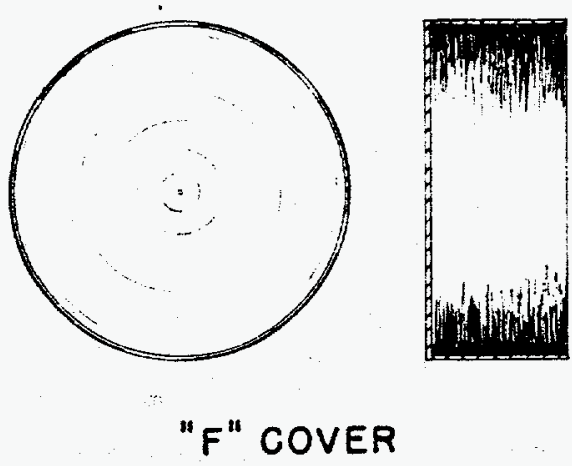

0
1
0
0

"E" ASSEMBLY

SAMPLE HOLDER.

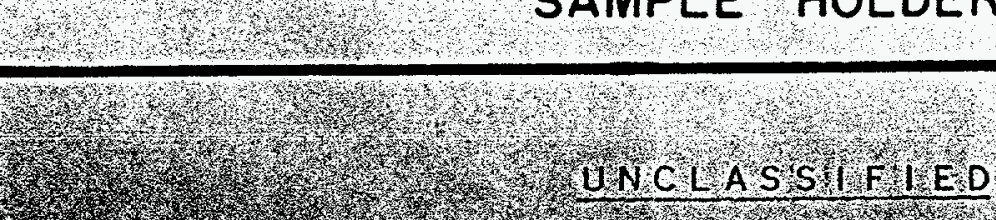




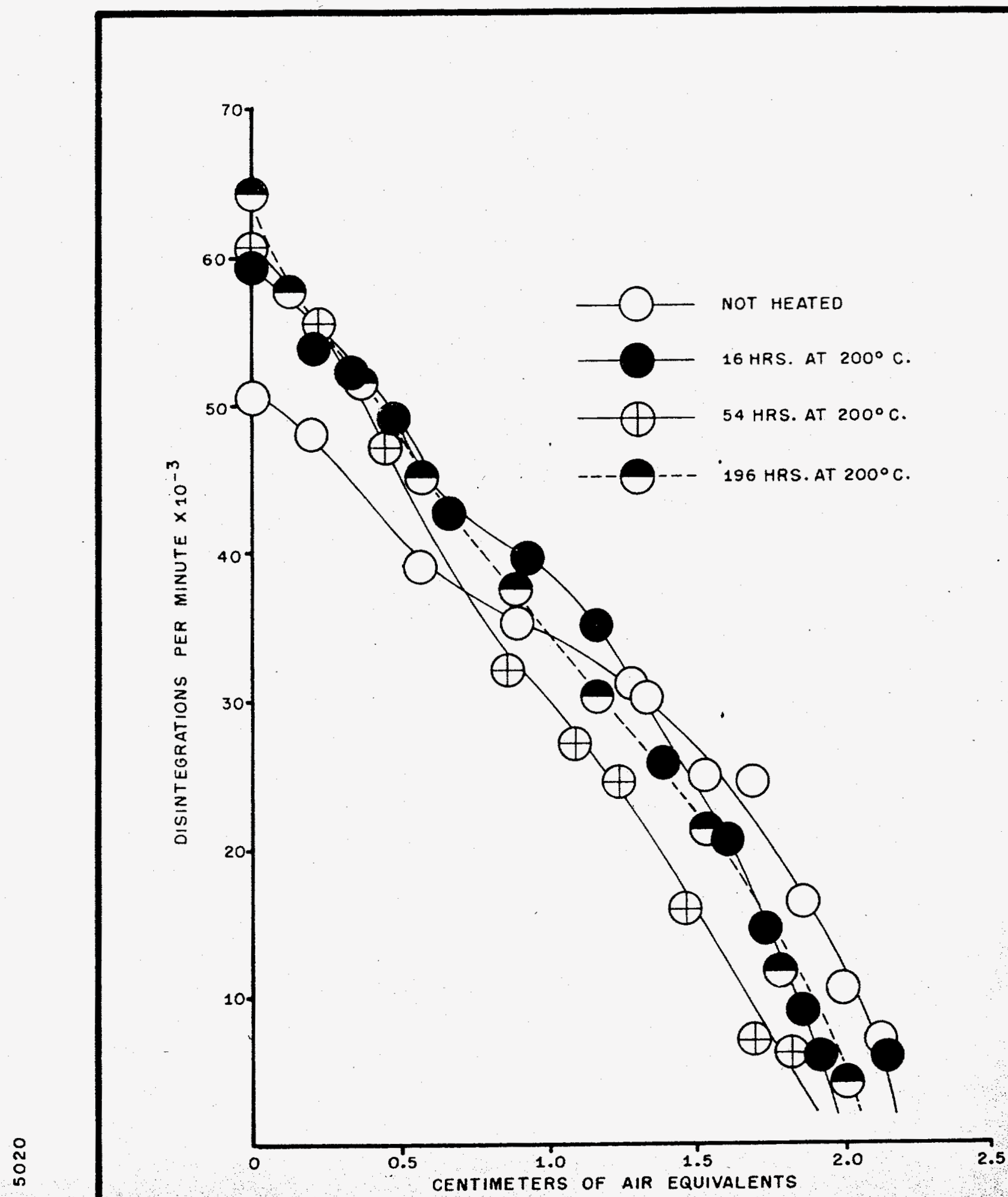

\section{STRAGGLING CURVES OF DIFFUSION SAMPLE.}




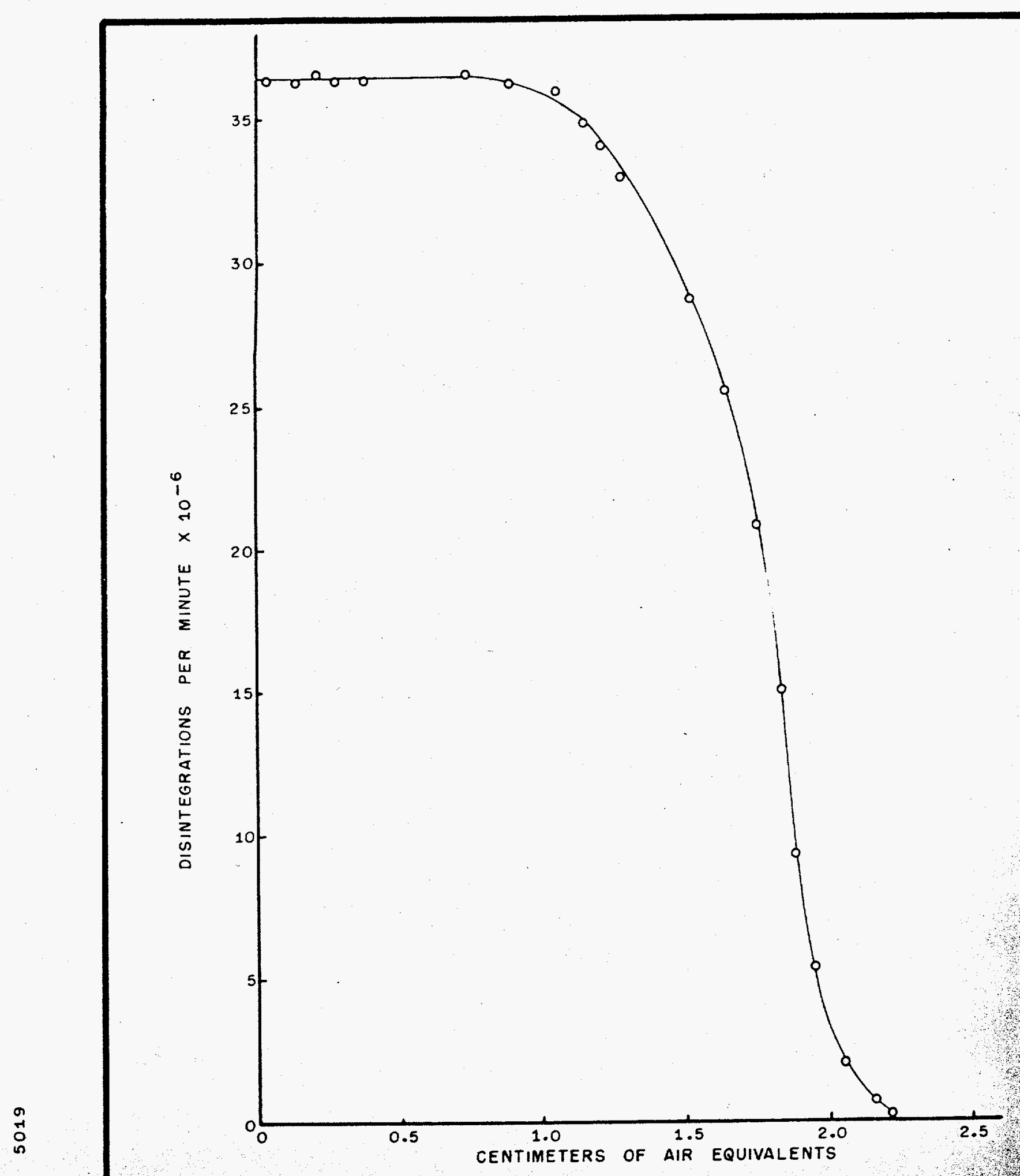

STRAGGLING CURVE OF BACK SIDE OF FOIL.

$\eta$ 


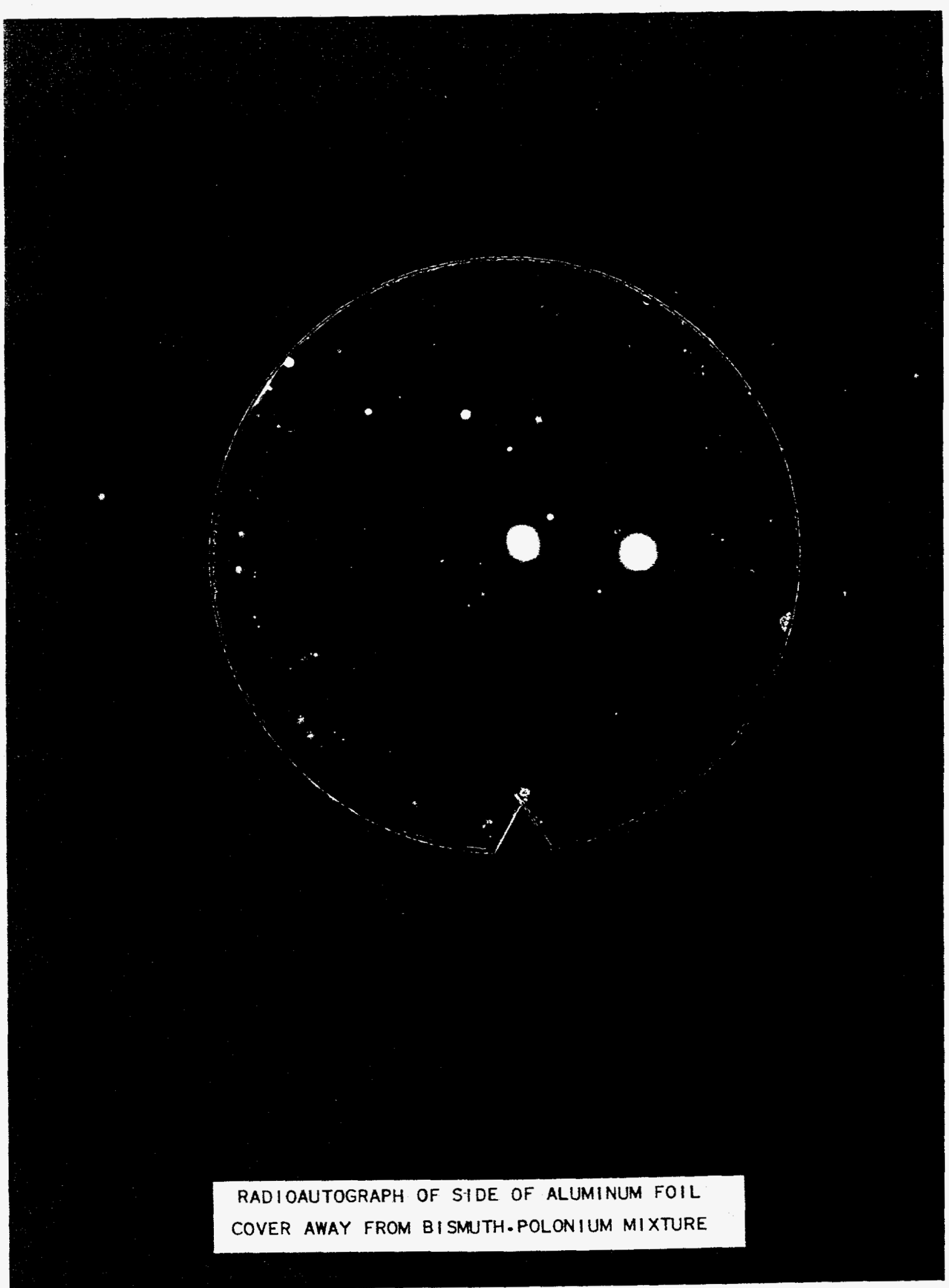

XSECPEC 


\author{
Problem Title - Loss of Polonium from an Uncovered Bismuth-Polonium Surface \\ Report By .- J. B. Otto, Jr., and W. H. Power \\ Work Done By - J. B. otto, Jr.
}

\title{
INTR ODUCTION
}

The degree of contamination of a cyclotron or linear accelerator to be expected when an irradiated bismuth surface is exposed in a vacuum system is of major concern for the polonium-208 program. Sufficient information regarding the rate of loss of polonium from an irradiated bismuth surface is desired to determine if contamination during irradiation will be great enough to deter the use of uncovered bismuth or if contamination will be of sufficiently low magnitude to be handled by routine cleaning.

The distribution of volatilized polonium in a vacuum system is being studied. ${ }^{1}$ The following report is concerned specifically with the rate of escape of polonium rather than with the distribution of activity.

\section{DETAILED REPORT}

\section{Apparatus}

An apparatus was constructed to permit.a bismuth polonium disk to be heated in a vacuum and the volatilized polonium collected immediately after its loss from the bismuth surface (Figure 1). The bismuth-polonium sample:holder was essentially the same as the holder used to study diffusion of polonium through aluminum. ${ }^{2}$ The aluminum foil of the diffusion apparatus was removed after assembly to expose the bismuth aluminum surface, one inch in diameter. The bottom of the holder was drilled and tapped to accept the end of a heating element from a soldering iron. The temperature of the sample.was recorded by means of a thermocouple inserted in the sample holder, A steel counting disk, held on a dry ice.. acetone cold finger by means of vacuum grease and a magnet, was mounted $1 / 16$ inch above the bismuth-polonium sample.

\section{Results}

A sample containing 4.88 millicuries of polonium per gram of bismuth was heated to $215^{\circ} \mathrm{C}$. during a 90 -minute period and was held at $215^{\circ} \mathrm{C}$. for 45 minutes. The pressure during the heating varied from $1.5 \times 10^{-3}$ to $2 \times 10^{4}$ millimeters of mercury. The.heating current was turned off and the system allowed to cool overnight. A radioautograph in. dicated that most of the activity on the disk was concentrated in a pattern similar to that of the circular bismuth-polonium sample (Figure 2 A), A small amount of polonium was deposited on the counting disk opposite the screw holes in the sample holder and in a circular area of greater diameter than the sample holder. The activity on the counting disk other than the one-inch diameter circle was masked off and the disk measured in an ionization chamber. An activity of $2.82 \times 10^{6}$ disintegrations per minute was found.

An autoradiograph of 20-hour exposure on the bismuth polonium sample and sample holder (Figure 2 B) confirmed that some activity had leaked through the screw holes. A 20-hour exposure of a strip of film placed around the side of the sample holder showed 
that some additional leakage of polonium had occurred through the joint. The uneven distribution of polonium in the bismuth-polonium sample, shown by a short-exposure radioautograph (Figure $2 \mathrm{C}$ ), is perhaps of considerable importance because it shows that some separation of bismuth and polonium occurred when the sample was cast.

The glass surface of the cold finger was rinsed with concentrated hydrochloric acid and the solution alpha counted. A total of $1 \times 10^{6}$ disintegrations per minute was in the acid. Rinses of the inside of the glass apparatus below the cold finger had a count of $1 \times 10^{5}$ disintegrations per minute. Although considerable polonium escaped through joints and screw holes of the sample holder, Radioautograph 2 A shows that activity volatilized from the exposed bismuth-polonium surface could be effectively.collected by the cold finger.

Additional experiments will be conducted to determine the effect of surface concentration and temperature upon the rate of loss of polonium from a bismuth-polonium surface.

\section{REFERENCES}

1. McCluggage, W. C., Rpt. Gen. Res., MLM-559, p. 20, May 21,1951 , and McCl uggage, W. C., This Volume, p. 16

2. Otto, J, B. Jr., This Volume, p. 43.

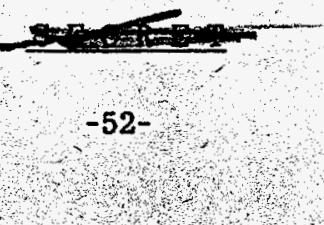




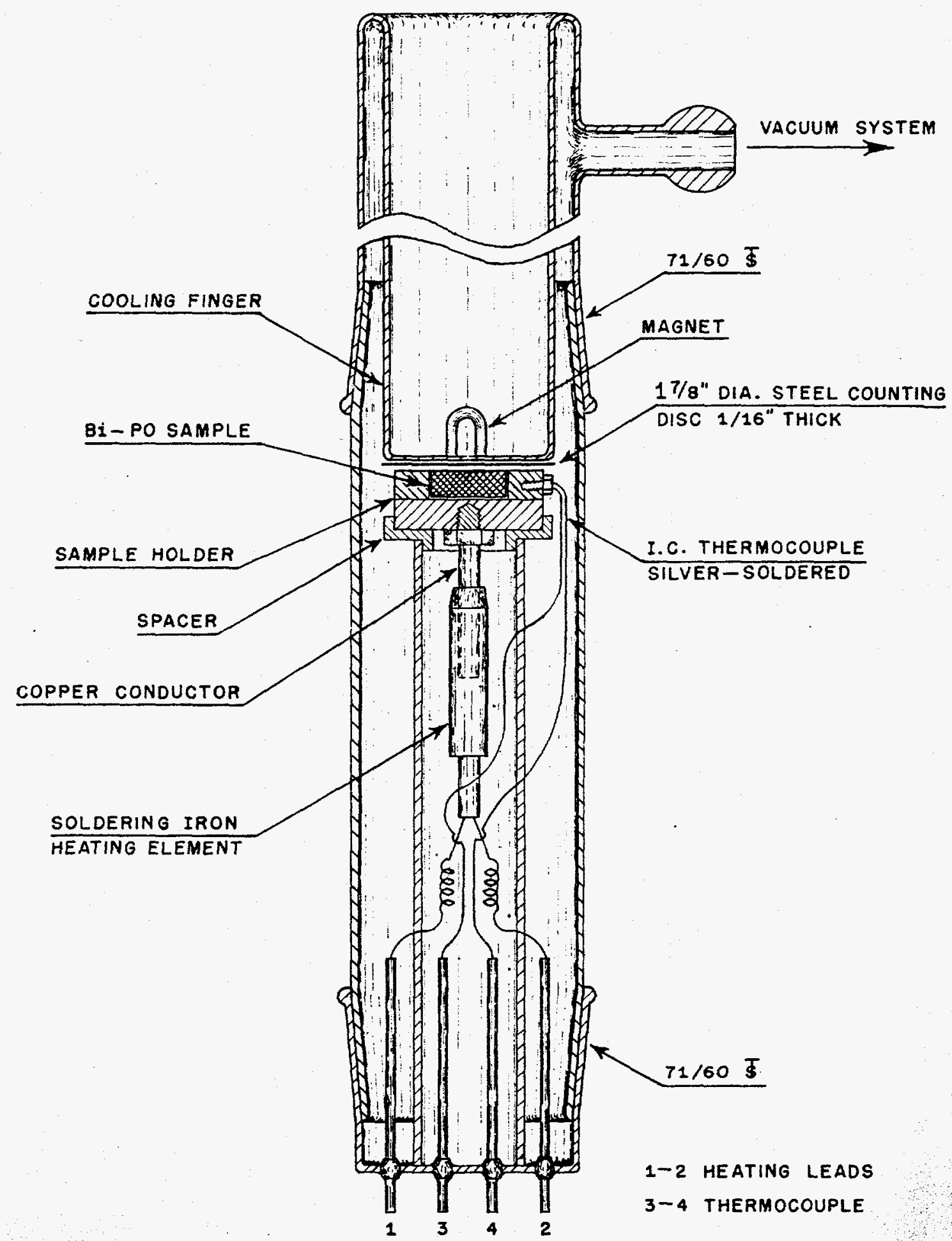

APPARATUS FOR DETERMINATION OF LOSS OF POLONIUM FROM A BISMUTH POLONIUM SURFACE. 


\section{Powret \\ nuTURADI OGRAPHS}

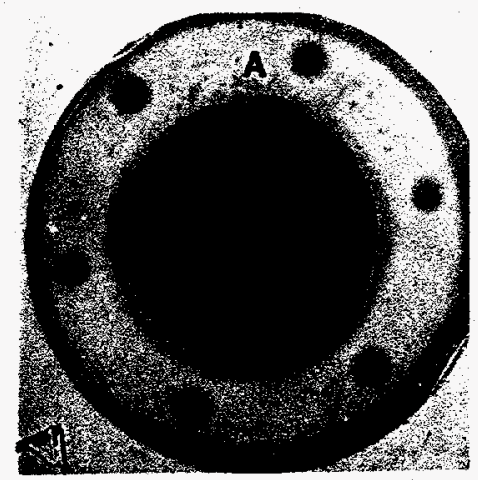

COUNTING DISK

(20.HOUR EXPOSURE)

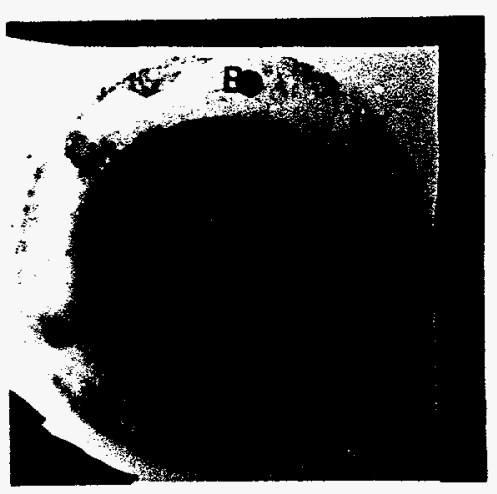

BISMUTH -POLOMIUM 'SAMPLE AND HOLDER

.(20-HOUR EXPOSURE)

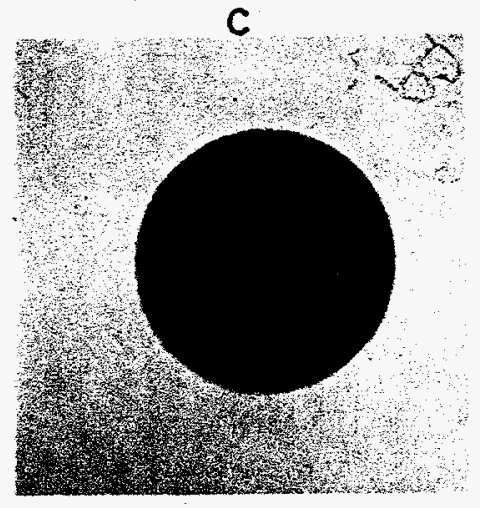

BISMUTH-POLONIUM DISK

(2.MINUTE EXPOSURE)

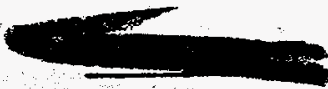

